\title{
Reatividade vascular da artéria mamária interna: estudos farmacológicos comparativos entre artérias caninas direita e esquerda
}

\author{
Paulo Roberto B. EVORA*, Paul J. PEARSON**, Marilyn OELTJEN**, \\ Berent DISCIGIL**, Hartzell V. SCHAFF**
}

RBCCV 44205-473

\begin{abstract}
Evora P R B, Pearson P J, Oeltjen M, Discigil B, Schaff H V - Reatividade vascular da artéria mamária interna: estudos farmacológicos comparativos entre artérias caninas direita e esquerda. Rev Bras Cir Cardiovasc 1999; 14 (4): 308-24.
\end{abstract}

RESUMO: Para estudos comparativos da reatividade vascular entre artéria mamária interna (AMI) canina direita e esquerda, realizaram-se experimentos "in vitro" utilizando-se banhos orgânicos ("organ chambers") e ensaios biológicos: 1) os produtos plaquetários ADP e 5-HT induziram, respectivamente, vasodilatação dependente e independente do endotélio; 2) os autacóides, bradicinina e histamina, também induziram vasodilatação, respectivamente, dependente e independente do endotélio; 3) o A23187, vasodilatador independente de receptor, induziu relaxamentos dependentes do endotélio; 4) dopamina, dobutamina, papaverina e a poli-L-arginina induziram vasodilatações independentes do endotélio; 5) a NOR induziu intensa vasoconstrição comparável à causada pelo $\mathrm{KCl}$ e pela endotelina; 6) em $83 \%$ de 24 ensaios, a liberação basal de NO foi maior na AMI esquerda, em comparação com a AMI direita; 7) ensaios biológicos de AMIs demonstraram a importância da $\mathrm{PGI}_{2}$ nas condições de hipóxia, uma vez que a indometacina aboliu vasodilatação adicional em resposta à hipóxia em condições de vasodilatação induzida pela liberação basal de NO; 8) não ocorreram diferenças significantes de resposta, comparando-se estudos realizados em AMIs direita e esquerda.

DESCRITORES: Artérias mamárias, efeitos de drogas. Endotélio vascular, efeitos de drogas. Neurotransmissores, farmacologia. Autacóides, farmacologia. Anóxia, metabolismo. Óxido nítrico, metabolismo. Epoprostenol, metabolismo. Bioensaios.

\section{INTRODUÇÃO}

O colapso cardiovascular é uma complicação potencialmente catastrófica após a revascularização cirúrgica do miocárdio (1). A etiologia da insuficiência cardíaca no pós-operatório desta cirurgia é diverso, mas o espasmo dos enxertos tem sido implicado como um fator contribuinte em inúmeros casos $(2,3)$. A introdução da artéria mamária interna (AMI) como enxerto vascular levou vários laboratórios, em todo o mundo, a estudar as causas de vasoespasmo, pelo perigo de fluxos inadequados através destes

\footnotetext{
Trabalho realizado na Divisão de Cirurgia Torácica e Cardiovascular da Mayo Clinic, Laboratório de Função Endotelial. Rochester, MN, Estados Unidos da América.

Apresentado ao $26^{\circ}$ Congresso Nacional de Cirurgia Cardíaca. Fortaleza, CE, 8 a 10 de abril, 1999.

* Da Divisão de Cirurgia Experimental do Departamento de Cirurgia, Ortopedia e Traumatologia da Faculdade de Medicina de Ribeirão Preto da Universidade de São Paulo e CECORP - Centro. Especializado do Coração e Pulmão de Ribeirão Preto.

** Da Divisão de Cirurgia Torácica e Cardiovascular da Mayo Clinic (Rochester, MN).

Endereço para correspondência: Paulo Roberto Evora. Rua Rui Barbosa, 367, Apto. 7. Ribeirão Preto, SP, Brasil. CEP: 14015-120. Tel (016) 636-4149.

Fax (016) 610-9890. e-mail: prbevora@keynet.com.br
} 
Evora P R B, Pearson P J, Oeltjen M, Discigil B, Schaff H V-Reatividade vascular da artéria mamária interna: estudos farmacológicos comparativos entre artérias caninas direita e esquerda.

Rev Bras Cir Cardiovasc 1999; 14 (4): 308-24

vasos relativamente finos. Comparada com outros enxertos arteriais utilizados para a revascularização do miocárdio, a AMI tem uma lâmina elástica relativamente larga ${ }^{(4)}$. Entretanto, ela também tem uma grande massa muscular lisa, e, portanto, considerável potencial para vasodilatação ou vasoconstrição. O tono vascular é controlado pelo óxido nítrico, estímulos que podem aumentar ou diminuir sua produção e liberação pelo enxerto podem, secundariamente, aumentar ou diminuir a perfusão coronariana.

A AMI tem sido estudada, também, no sentido de se entender a sua excelente patência como enxerto a longo prazo e a sua resistência à aterosclerose, quando comparada com outras artérias. Alguns investigadores têm sugerido que esta característica da AMI possa ser devida a um aumento da produção de óxido nítrico, que é um nitrovasodilatador endógeno sintetizado pela sua íntima, representada pelo endotélio $(5,6)$.

Estes fatos motivaram o presente estudo, que teve por objetivo: 1) estudar os efeitos das drogas cardiovasculares freqüentemente usadas, autocóides e produtos plaquetários; 2) comparar a reatividade das AMIs direita e esquerda; 3) estudar o papel da prostaciclina $\left(\mathrm{PGI}_{2}\right)$ e do óxido nítrico (NO) nas condições de hipóxia e normóxia; 4) determinar se a AMI canina é um modelo fisiológico aceitável quando comparada com a AMI humana utilizada em revascularização do miocárdio e; 5) estudar o efeito de agonistas administrados dentro (intraluminal) ou fora do vaso (extraluminal).

\section{MATERIAL E MÉTODOS}

Cães mestiços sem verminose $(25-30 \mathrm{~kg})$, de ambos os sexos, foram anestesiados com pentobarbital sódico (injeção em bolo endovenoso de 30 $\mathrm{mg} / \mathrm{kg}$, Fort Dodge Laboratories) e exanguinados via artérias carótidas. As artérias mamárias direita e esquerda foram dissecadas cuidadosamente através de toracotomia e mantidas em solução fisiológica salina, oxigenada e fria, com a seguinte composição milimolar: $\mathrm{NaCl}, 118.3 ; \mathrm{KCl}, 4.7 ; \mathrm{MgSO}_{4}$, 1.2; $\mathrm{KH}_{2} \mathrm{PO}_{4}, 1.22 ; \mathrm{CaCl}_{2}, 2.5 ; \mathrm{NaHCO}_{3}, 25.0$, e glicose, 11.1 (solução controle). Os procedimentos e cuidados dos animais foram revisados e aprovados pelo Institutional Animal Care and Use Committee of the Mayo Foundation.

Os estudos da reatividade vascular foram realizados utilizando-se dois sistemas experimentais "in vitro": banhos orgânicos ("organ chambers") e ensaios biológicos em cascata.

Metodologia e Protocolo dos Estudos em Sistema de "Organ Chambers"

Os banhos orgânicos ("organ chambers") são construídos em vidro e constituem-se em uma dupla câmara por onde circula, constantemente, água a uma temperatura mantida a $37^{\circ} \mathrm{C}$ em circuito fechado, e um reservatório com um volume constante de $25 \mathrm{ml}$, onde os anéis vasculares são suspensos e onde as drogas são adicionadas. Este reservatório é preenchido por uma solução de Krebs modificada e, comunica-se a um sistema de aspiração a vácuo e a um sistema de aeração, permitindo os estudos em situações de normóxia ou hipóxia. A solução de Krebs pode ser renovada sempre que o experimento exigir, combinando-se a aspiração com reintrodução de solução nova a qual fica contida em uma torre de vidro, que à semelhança das "organ-chambers", também é mantida a $37^{\circ} \mathrm{C}$ e com aeração contínua.

O segmento de anel vascular é suspenso entre alças de aço inoxidável, passando através de sua luz. Antes de iniciar-se os experimentos farmacológicos, propriamente ditos, os vasos são submetidos ao seu ponto ótimo de tensão-estiramento, por meio de um sistema micrométrico. As tensões isométricas são registradas por um sistema de sensíveis transdutores de pressão (Statham UC 2) acoplados, individualmente, a cada anel vascular e ligados a um registrador de oito canais (Gould, Cleveland, Ohio). Os experimentos são realizados em um conjunto, em paralelo, de oito "organ chambers". Para cada anel vascular com endotélio estuda-se um anel sem endotélio como controle (Figura 1).

Em nossos experimentos suspendemos em "organ-chambers" os anéis vasculares, com e sem endotélio, de artérias mamárias internas caninas direita e esquerda. Estes anéis, como procedimento básico para o estudo farmacológico em "organ chambers", foram colocados em seu ponto ótimo de tensão-estiramento $(10 \mathrm{~g})$ em presença de indometacina. Após testar-se a presença ou não de endotélio pelo uso de acetilcolina, os vasos permaneceram em repouso pelo espaço de tempo mínimo de 30 minutos, findos os quais foram contraídos com norepinefrina $\left(10^{-5} \mathrm{M}\right)$ e submetidos a testes farmacológicos (curvas dose-respostas).

\section{Metodologia e Protocolo dos Estudos em Sistema para Ensaios Biológicos}

Para os ensaios biológicos os segmentos vasculares ( 3 a $5 \mathrm{~cm}$ ), tendo todos os seus ramos ligados, são canulados com cânulas de aço inoxidável (diâmetro interno de 0.5 a $1.5 \mathrm{~mm}$ ), em um sistema de três vias: duas para perfusão de vasos (com ou sem endotélio), e uma via direta para perfusão do anel vascular, sem endotélio, a ser submetido aos possíveis efeitos de substâncias liberadas, espontaneamente, ou por meio de estimulação farmacológica, pelos dois segmentos vasculares. Os vasos são mantidos em uma "organ chamber" 


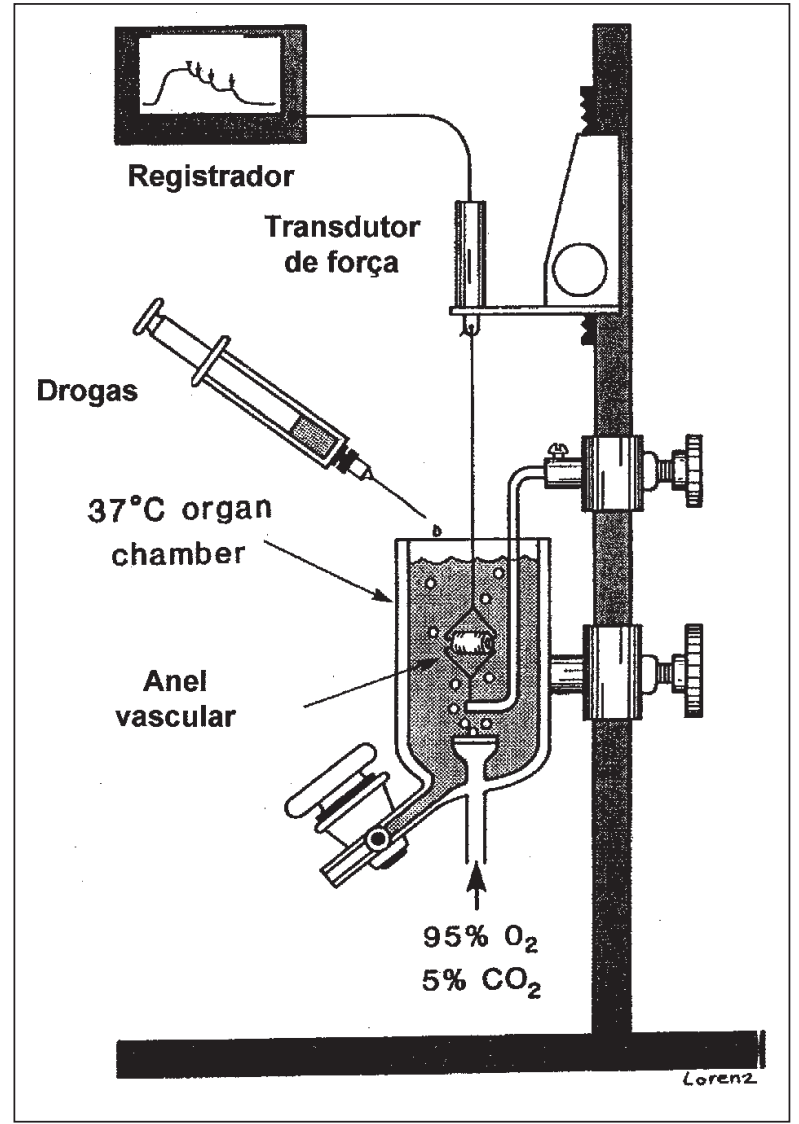

Fig. 1 - Representação esquemática dos banhos orgânicos ("organ chambers") utilizados para o estudo da reatividade vascular das artérias mamárias.

de vidro $(25 \mathrm{ml})$, preenchida com solução de Krebs a $37^{\circ} \mathrm{C}$ e aerada $\left(95 \% \mathrm{O}_{2}-5 \% \mathrm{CO}_{2}\right)$. Os segmentos vasculares são perfundidos a um fluxo constante $(5$ $\mathrm{ml} / \mathrm{min}$ ) com auxílio de uma bomba de rolete. A linha direta também é perfundida com o mesmo fluxo. Para os estudos em condição de normóxia os banhos orgânicos foram aerados com $95 \% \mathrm{O}_{2} / 5 \% \mathrm{CO}_{2}$ e para hipóxia $95 \% \mathrm{~N}_{2} / 5 \% \mathrm{CO}_{2}$. Para os estudos em condições de hipóxia os banhos orgânicos foram aerados com $95 \% \mathrm{~N} / 5 \% \mathrm{CO}_{2}, \mathrm{pO}_{2}=50 \mathrm{mmg}, \mathrm{pH}=7,4 \mathrm{na}$ presença ou não da indometacina.

Um anel vascular, o qual tem seu endotélio removido ("bioassay ring"), é suspenso, diretamente abaixo da "organ chamber", entre duas alças de aço inoxidável, e conectado a um transdutor de pressão. As alterações da força isométrica podem, assim, serem registradas. O conjunto de "bioassay ring", alças de suspensão e transdutor de pressão pode ser, cuidadosamente, movido em direção ao gotejamento escolhido de acordo com o protocolo experimental (linhas de perfusão vasculares ou linha direta). As possíveis alterações assim detectadas indicam, ou não, a liberação de fatores pelo endotélio do vaso perfundido. Podem-se adicionar drogas abluminal (na solução de Krebs da "organ chamber") ou intraluminal. As infusões intraluminares de drogas podem ser feitas antes (sítio 1) ou, imediatamente, após a superfusão vascular (Figura 2).

Em nossos experimentos as artérias mamárias internas foram perfundidas com um fluxo constante de $5 \mathrm{ml} / \mathrm{min}$ com solução salina fisiológica a $37^{\circ} \mathrm{C}$. Existiu, aproximadamente, um retardo de um segundo após o fluido alcançar o anel de ensaio biológico - qual é suspenso logo abaixo dos segmentos arteriais com endotélio mantidos em uma "organchambers". As atividades tencionais desenvolvidas pelo anel de ensaio biológico foram registradas para a quantificação dos efeitos produzidos pela liberação de fatores vasoativos do endotélio dos segmentos de artérias mamárias internas perfundidas a um fluxo constante. Os anéis coronarianos sem endotélio ("bioassay rings") foram, inicialmente, superfundidos por cerca de $60 \mathrm{~min}$, durante os quais obtiveram-se seus pontos ótimos de tensão-estiramento $(10 \mathrm{~g})$. Após 30 min, contraíram-se os "bioassay rings" pela superfusão de prostaglandina F2. A ausência de endotélio nestes anéis foi confirmada pela injeção de acetilcolina na linha direta do sistema de superfusão. Após todos estes cuidados técnicos os "biossay rings" foram testados pelos efeitos obtidos pela superfusão através dos segmentos das artérias mamárias (superfusão endotelial). Em alguns expe-

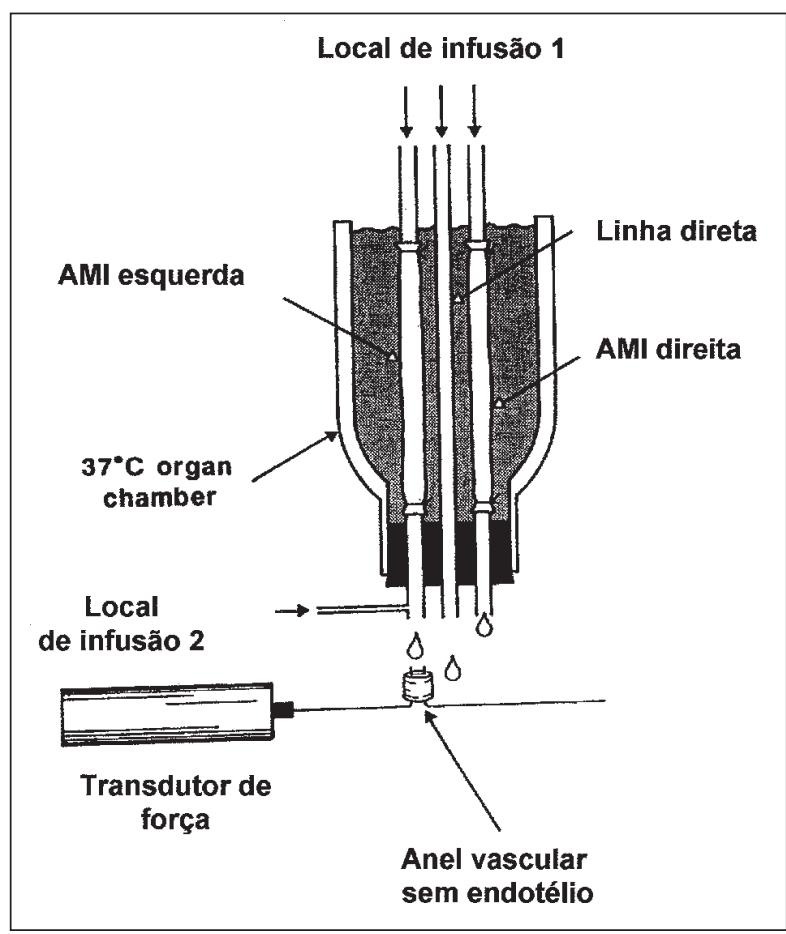

Fig. 2 - Representação esquemática do sistema de ensaio biológico ("biological assay") utilizado em estudos das artérias mamárias. 
Evora P R B, Pearson P J, Oeltjen M, Discigil B, Schaff H V-Reatividade vascular da artéria mamária interna: estudos farmacológicos comparativos entre artérias caninas direita e esquerda.

Rev Bras Cir Cardiovasc 1999; 14 (4): 308-24

rimentos removeu-se o endotélio de ambas artérias mamárias utilizando-se um pequeno probe de aço inoxidável. Sempre que se utilizou este expediente, testou-se a ausência de endotélio pela injeção de acetilcolina $\left(10^{-7} \mathrm{M}\right)$. Após os estudos, os segmentos de artérias mamárias foram preservados em formalina, abertos longitudinalmente, fixados em cartões e fotografados. As superfícies destes vasos foram, então, medidas com auxílio de planimetria assistida por computador.

Para os ensaios biológicos de artérias mamárias, com a finalidade de testar as ações de agonistas administrados intraluminal ou extraluminal, segmentos de artéria mamária interna de cães foram suspensos em banho orgânico contendo solução salina fisiológica $\left(95 \% \mathrm{O}_{2} / 5 \% \mathrm{CO}_{2}, \mathrm{pH}=7,4,37^{\circ} \mathrm{C}\right)$. As artérias foram canuladas individualmente e perfundidas a $5 \mathrm{ml} / \mathrm{min}$ usando uma bomba de roletes.

A atividade vasorelaxante do efluente das artérias mamárias perfundidas foi bioensaiada pela medida da diminuição da tensão em anéis de coronárias sem endotélio e contraídos por prostaglandina $\mathrm{F}_{2 \alpha}\left(2 \times 10^{-6} \mathrm{M}\right)$. Os ensaios foram realizados na presença de prostaglandina, testando-se a liberação estimulada de óxido nítrico injetando-se os seguintes agonistas na luz da artéria (estimulação intraluminal) e no banho orgânico (estimulação extraluminal): acetilcolina $\left(10^{-5} \mathrm{M}\right), \mathrm{ADP}$ $\left(10^{-5} \mathrm{M}\right)$ e o cálcio ionóforo A23187 (10-5 M).

Drogas - As seguintes drogas foram utilizadas: acetilcolina $(\mathrm{ACH})$, difosfato de adenosina (ADP), bradicinina, ionóforo do cálcio (A23187), histamina, serotonina (5-HT), indometacina, norepinefrina (NOR), papaverina, poli-L-arginina, prostaglandina $F_{2 \alpha}$ $\left(\mathrm{PGF}_{2 \alpha}\right.$ ) (Sigma Chemical Company, St. Louis, MO). $N^{g}$-nitro-L-prostaglandina $F_{2 \alpha}\left(P F_{2 \alpha}\right)$ Sigma Chemical Company, St. Louis, MO). Ng-nitro-L-arginina (Calbiochem, San Diego, California), dopamina (Abbott Laboratories, North Chicago, IL), dobutamina (Eli Lilly Industries, Inc, Carolina, Puerto Rico) e endotelina (Peninsula Laboratories, Belmont, CA). Todas as drogas foram preparadas diariamente, sendo dissolvidas em água destilada, exceto a indometacina, a qual foi dissolvida em $\mathrm{Na}_{2} \mathrm{CO}_{3}\left(10^{-5} \mathrm{M}\right)$, e o ionóforo do cálcio A23187 que foi dissolvido em dimetilsulfóxido (Sigma) e diluído em água destilada.

Análise dos dados - Os resultados serão apresentados como média \pm erro-padrão. Em todos os experimentos, $\mathbf{n}$ significa o número de animais dos quais os anéis vasculares foram obtidos. Em anéis contraídos com prostaglandina $\mathrm{F}_{2 \alpha}$, as respostas foram expressas como porcentagem das alterações a partir da contração máxima estável. Estes valores foram utilizados para a construção de curvas doserespostas. Para a análise estatística foram utilizados a análise de variância (ANOVA) e o teste $\mathrm{T}$ de
Student para observações pareadas e não pareadas. Os valores foram considerados significantes quando o valor de $\mathbf{p}$ foi menor do que 0,05.

\section{RESULTADOS}

Estudos em Banhos Orgânicos ("Organ Chambers") de Artéria Mamária Direita e Esquerda

Neurotransmissor - Em segmentos de artérias contraídos com norepinefrina $\left(10^{-6} \mathrm{M}\right)$, a acetilcolina $\left(10^{-9}\right.$ a $\left.10^{-4} \mathrm{M}\right)$ causou relaxamento, dependente da concentração em segmentos de artérias mamárias direita e esquerda com endotélio, mas sem alterações significantes nas tensões de anéis vasculares sem endotélio (Figuras 3 e 4). A vasodilatação dependente do endotélio causada pela acetilcolina foi comparável nas artérias mamárias direita e esquerda (Figura 4). Esta vasodilatação foi inibida pela hemoglobina $\left(10^{-6} \mathrm{M}\right)$ ou pelo pré-tratamento com $N^{G}$-monometil-L-arginina $\left(10^{-5} \mathrm{M}\right)$. A indometacina $\left(10^{-5} \mathrm{M}\right)$ não afetou o relaxamento dependente do endotélio causado pela acetilcolina (Figura 4).

Produtos plaquetários - Em segmentos de artérias mamárias contraídos com norepinefrina, a adenosina difosfato (ADP) $\left(10^{-9}\right.$ a $\left.10^{-4} \mathrm{M}\right)$ induziu relaxamento dependente da concentração em anéis com endotélio o qual foi, significantemente, maior do que o relaxamento em anéis sem endotélio. Não houve nenhuma diferença em resposta ao ADP entre as artérias mamárias direita e esquerda. A serotonina (5-Hidroxitriptamina / 5-HT) $\left(10^{-9}\right.$ a $\left.10^{-4} \mathrm{M}\right)$ induziu relaxamento dependente da concentração em segmentos de artérias mamárias com e sem endotélio (Figura 5). Não houve nenhuma diferença significante

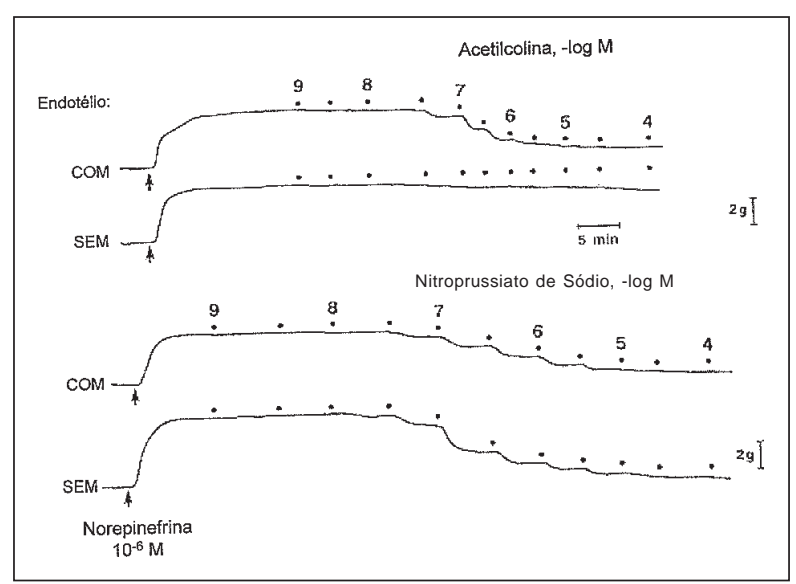

Fig. 3 - Relaxamentos dependentes do endotélio (acetilcolina) e independente de endotélio (nitroprussiato de sódio) de artérias mamárias internas caninas (traçado original). Suspenderamse os segmentos de artérias mamárias, com e sem endotélio, em "organ-chambers". Após estabilização da contração produzida pela norepinefrina, utilizaram-se concentrações crescentes de acetilcolina e nitroprussiato de sódio. 


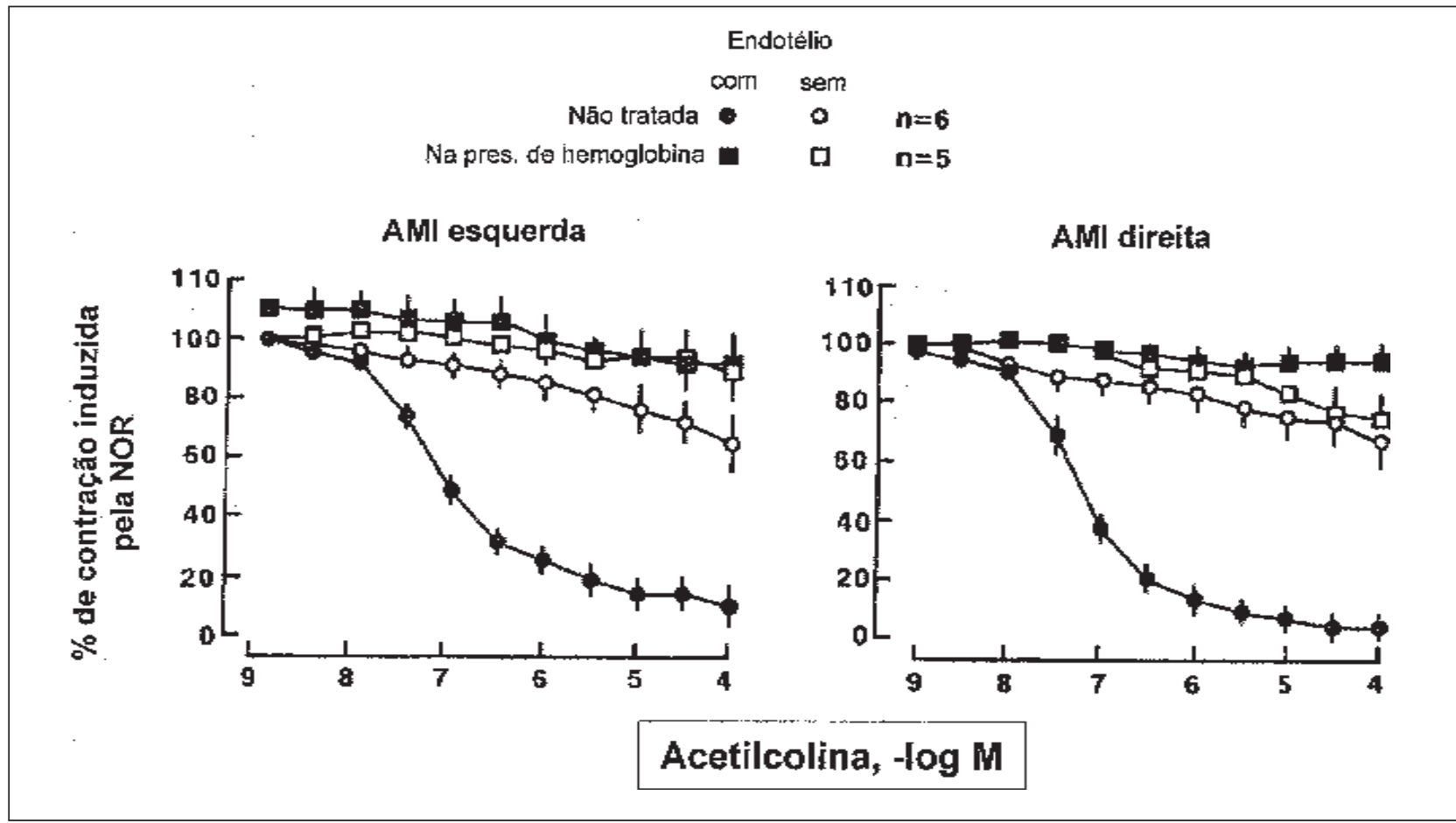

Fig. 4 - Curvas dose-respostas à acetilcolina $\left(10^{-9}\right.$ a $\left.10^{-4} \mathrm{M}\right)$ em artérias mamárias interna caninas direita e esquerda. Apresentam-se os valores sob a forma de médias \pm erros-padrões, os quais representam a mudança das tensões a partir da contração inicial produzida pela norepinefrina (100\%). Utilizou-se indometacina na concentração de $10^{-5} \mathrm{M}$.

nos relaxamentos causados pela serotonina comparando-se anéis com e sem endotélio, ou comparandose as artérias mamárias direita e esquerda (Tabela 1).
Autacóides - A bradicinina $\left(10^{-9}\right.$ a $\left.10^{-4} \mathrm{M}\right)$ induziu relaxamento dependente da concentração em segmentos de artérias mamárias com endotélio o

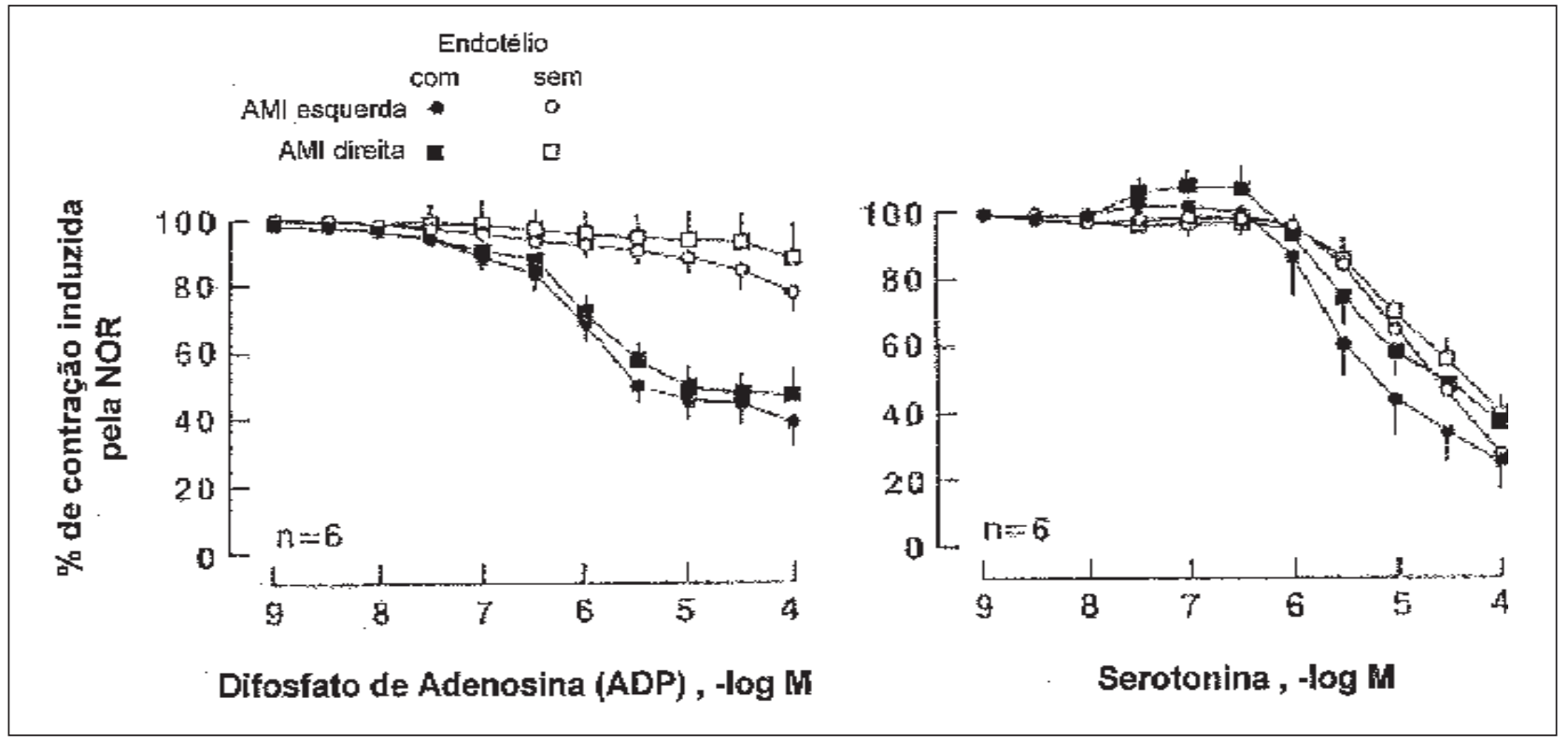

Fig. 5 - Curvas dose-respostas aos produtos plaquetários difosfato de adenosina (ADP) e 5-hidroxitriptamina (serotonina ou 5-HT) em artérias mamárias internas caninas direita e esquerda, com e sem endotélio. Apresentam-se os valores sob a forma de médias \pm erros-padrões, os quais representam a mudança das tensões a partir da contração inicial produzida pela norepinefrina $(60 \%$ da contração máxima a este composto). Utilizou-se indometacina na concentração de $10^{-5} \mathrm{M}$. 
Evora P R B, Pearson P J, Oeltjen M, Discigil B, Schaff H V-Reatividade vascular da artéria mamária interna: estudos farmacológicos comparativos entre artérias caninas direita e esquerda. Rev Bras Cir Cardiovasc 1999; 14 (4): 308-24

TABELA 1

VALORES PARA 50\% DE INIBIÇÃO (-LOG M) DAS ARTÉRIAS MAMÁRIAS DIREITA E ESQUERDA, COM E SEM ENDOTÉLIO

\begin{tabular}{lcccc}
\hline \multirow{2}{*}{ AGONISTA } & \multicolumn{2}{c}{ ARTÉRIA MAMÁRIA INTERNA DIREITA } & ARTÉRIA MAMÁRIA INTERNA ESQUERDA \\
\cline { 2 - 5 } & COM ENDOTÉLIO & SEM ENDOTÉLIO & COM ENDOTÉLIO & SEM ENDOTÉLIO \\
\hline A23187 & $7,45 \pm 0,10$ & $\dagger$ & $7,54 \pm 0,80$ & $\dagger$ \\
Bradicinina & $6,85 \pm 0,18$ & $\dagger$ & $6,85 \pm 0,16$ & $\dagger$ \\
Dobutamina & $5,86 \pm 0,25$ & $5,90 \pm 0,28$ & $5,77 \pm 0,33$ & $5,96 \pm 0,30$ \\
Papaverina & $5,08 \pm 0,15$ & $4,99 \pm 0,18$ & $4,94 \pm 0,21$ & $5,07 \pm 0,13$ \\
Poli-L-arginina & $7,95 \pm 0,21$ & $7,84 \pm 0,18$ & $7,97 \pm 0,10$ & $8,24 \pm 0,18$ \\
Serotonina & $5,03 \pm 0,32$ & $4,61 \pm 0,17$ & $4,68 \pm 0,27$ & $4,40 \pm 0,14$ \\
\hline
\end{tabular}

Apresentam-se os valores em gramas (média \pm erro-padrão)

$\dagger=0$ agonista não induziu relaxamento significante para esta preparação.

qual foi, significantemente, maior do que a resposta dos anéis sem endotélio. Não houve nenhuma diferença significante entre as artérias mamárias direita e esquerda (Tabela 1$)$. A histamina $\left(10^{-9}\right.$ a $\left.10^{-4} \mathrm{M}\right)$ induziu comparável relaxamento dependente da concentração em anéis de artérias mamárias com e sem endotélio. Não houve nenhuma diferença nas respostas à histamina com e sem endotélio entre as artérias mamárias direita e esquerda (Figura 6).

Agonista da liberação do óxido nítrico independente de receptor - O cálcio ionóforo A23187 $\left(10^{-9}\right.$ a $\left.10^{-6} \mathrm{M}\right)$ causou relaxamento concentração dependente em segmentos de artérias mamárias direita e esquerda com endotélio, mas nenhuma alteração significante nos anéis sem endotélio (Figura 7).
A vasodilatação dependente do endotélio causada pelo A23187 foi inibida pela hemoglobina $\left(10^{-5} \mathrm{M}\right) \mathrm{e}$ pelo pré-tratamento dos segmentos vasculares com $\mathrm{N}^{\mathrm{G}}$-nitro-L-arginina $\left(10^{-4} \mathrm{M}\right)$ (Figura 7).

Agonista independente do óxido nítrico - $A$ poli-L-arginina $\left(10^{-11}\right.$ a $\left.10^{-7} \mathrm{M}\right)$ (Figura 8) induziu relaxamentos dependentes da concentração comparáveis em segmentos de artérias mamárias direita e esquerda com e sem endotélio (Tabela 1).

Drogas cardiovasculares - A papaverina $\left(10^{-9}\right.$ a $\left.10^{-4} \mathrm{M}\right)$ (Figura 8), dopamina $\left(10^{-9}\right.$ a $\left.10^{-4} \mathrm{M}\right)$, a dobutamina $\left(10^{-9}\right.$ a $\left.19^{-4} \mathrm{M}\right)$ (Figura 9), e o nitroprussiato de sódio (Figura 10) induziram relaxamentos dependentes da concentração comparáveis

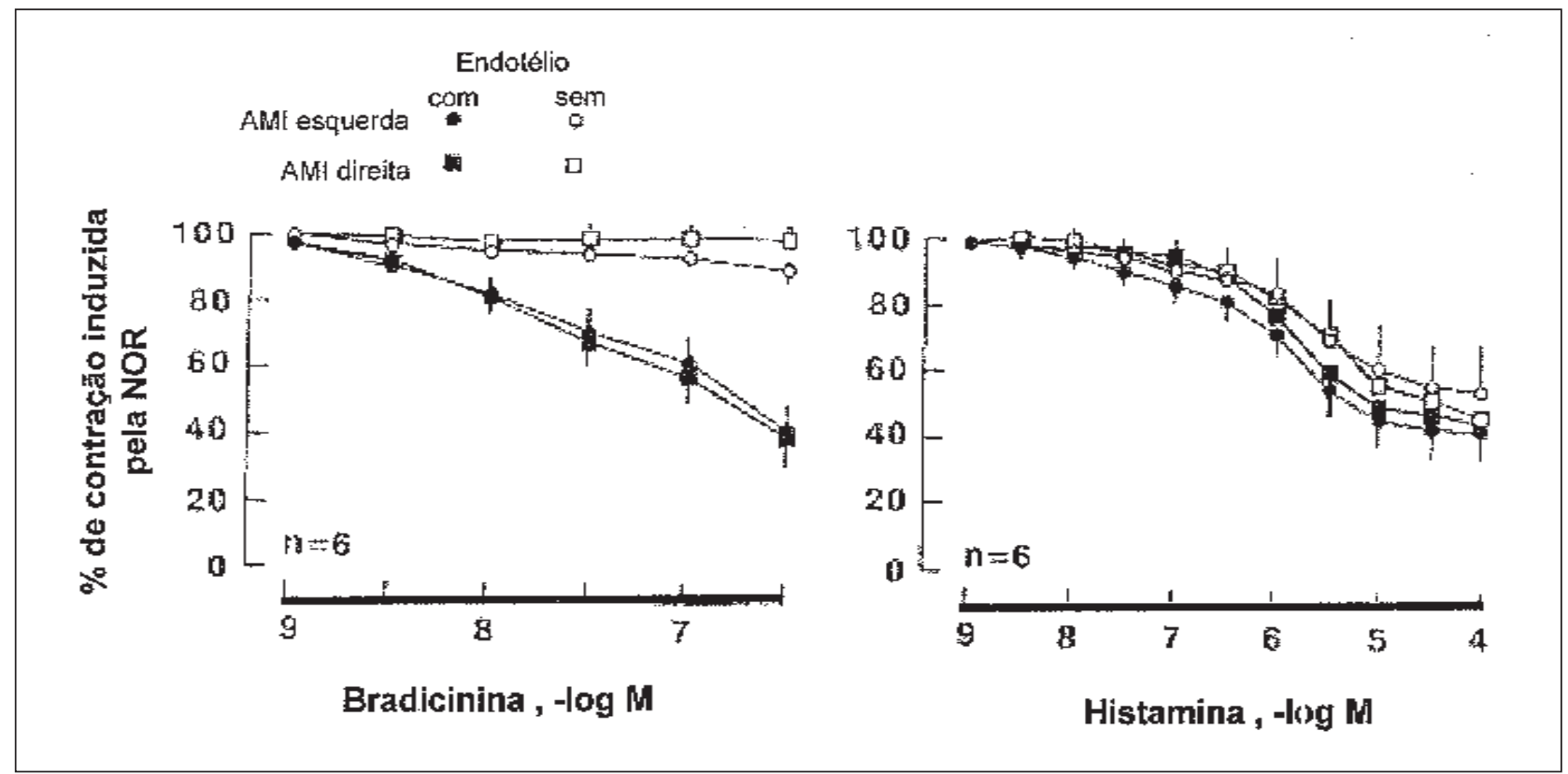

Fig. 6 - Curvas dose-respostas à bradicinina e à histamina em artérias mamárias internas caninas direita e esquerda, com e sem endotélio. Apresentam-se os valores sob a forma de médias \pm erros-padrões, os quais representam a mudança das tensões a partir da contração inicial produzida pela norepinefrina ( $60 \%$ da contração máxima a este composto). Utilizou-se indometacina na concentração de $10^{-5} \mathrm{M}$. 
Evora P R B, Pearson P J, Oeltjen M, Discigil B, Schaff H V - Reatividade vascular da artéria mamária interna: estudos farmacológicos comparativos entre artérias caninas direita e esquerda.

Rev Bras Cir Cardiovasc 1999; 14 (4): 308-24

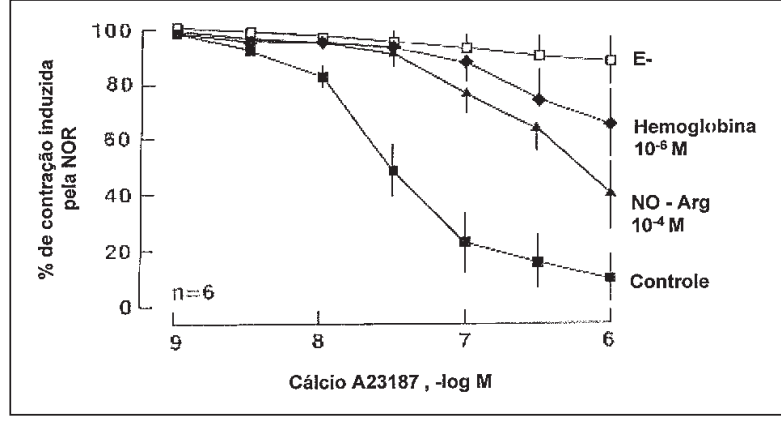

Fig. 7 - Curvas dose-respostas ao cálcio ionóforo A23187 em seg mentos de artérias mamárias internas caninas esquerdas com e sem endotélio. Apresentam-se os valores sob a forma de médias \pm erros-padrões, os quais representam a mudança das tensões a partir da contração inicial produzida pela norepinefrina ( $60 \%$ da contração máxima a este composto). Utilizou-se indometacina na concentração de $10^{-5} \mathrm{M}$. Adicionaram-se a hemoglobina $\left(10^{-5} \mathrm{M}\right)$ (traçado superior) ou $\mathrm{N}^{\mathrm{G}}$. nitro-L-arginina (NO-ARG) $\left(10^{-4} \mathrm{M}\right)$ (traçado inferior), quando utilizadas, pelo menos 10 minutos antes da contração com a norepinefrina.

em segmentos de artérias mamárias direita e esquerda com e sem endotélio (Tabela 1).

Vasoconstritores - O íon potássio ( $5 \mathrm{mM}$ a 60 $\mathrm{mM})$ e a endotelina-1 $\left(10^{-13}\right.$ a $\left.10^{-7} \mathrm{M}\right)$ induziram contração dependente da concentração em segmentos de artérias mamárias com e sem endotélio (Tabela 2). A norepinefrina $\left(10^{-9}\right.$ a $\left.10^{-4} \mathrm{M}\right)$ induziu contração dependente da concentração em segmentos de artérias mamárias direita e esquerda com e sem endotélio (Figura 11). Não houve nenhuma diferença significante nas contrações cau- sadas pela norepinefrina em vasos com e sem endotélio e nem entre as artérias mamárias direita e esquerda.

\section{Estudos Utilizando Ensaios Biológicos em Artérias Mamárias Internas Direita e Esquerda}

Após a contração do segmento de artéria coronária sem endotélio ("bioassay ring"), pela adição de prostaglandina $\mathrm{F}_{2 \alpha}\left(2 \times 10^{-8} \mathrm{M}\right)$ ao perfusato, mudando-se o gotejamento do perfusato da linha metálica (superfusão direta) para o gotejamento do perfusato através dos segmentos das artérias mamárias direita e esquerda (superfusão endotelial), obteve-se um relaxamento estável do "bioassay ring" indicando uma liberação basal de EDRF (Figura 12). Este relaxamento, induzido pela superfusão através das artérias mamárias pode ser prevenido pela remoção mecânica dos seus endotélios, pela adição de $N^{G}$-monometil-L-arginina $\left(10^{-4} \mathrm{M}\right)$ ou $N^{G}$-nitro-Larginina $\left(10^{-4} \mathrm{M}\right)$ ao perfusato (Figuras 12 e 13). A adição de indometacina $\left(10^{-5} \mathrm{M}\right)$ não afetou a atividade vasodilatadora dos efluentes de ambas artérias mamárias (Figuras 12 e 13).

Em 20 de 24 experimentos (83\%), a artéria mamária esquerda apresentou maior liberação de EDRF do que a correspondente artéria direita (Figura 14). Acresça-se que a vasodilatação média causada pela artéria mamária esquerda foi de 28.9 $\pm 2.3 \%$ contra $17.4 \pm 3.1 \%$ para a mamária direita $(p<0,05)$ (Figura 14). O maior relaxamento induzido pela artéria mamária esquerda foi independente da

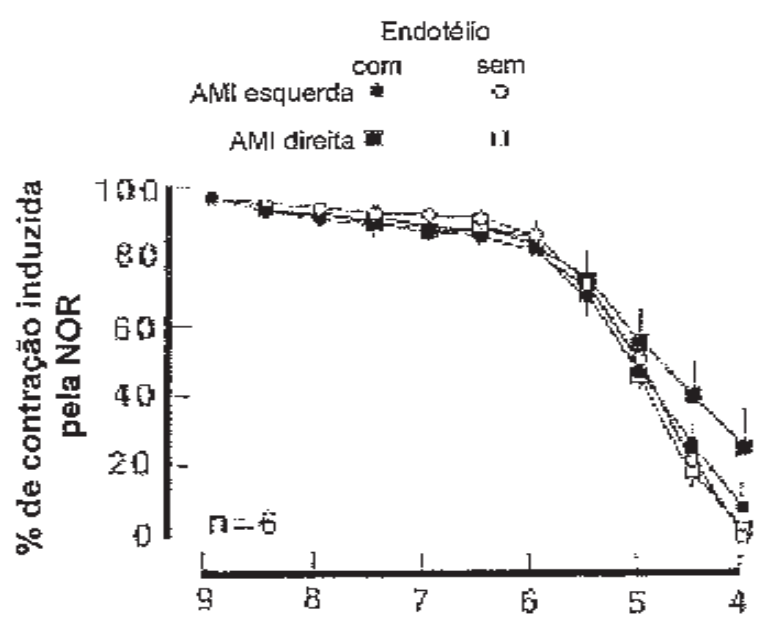

Papaverina , $-\log M$

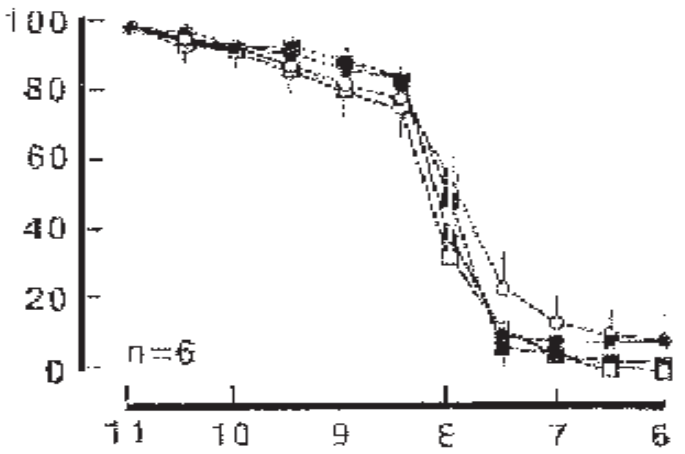

Poli - L. - Arginina , -log M

Fig. 8 - Curvas dose-respostas à papaverina e à poli-L-arginina (PM =139,200) em artérias mamárias internas caninas direita e esquerda, com e sem endotélio. Apresentam-se os valores sob a forma de médias \pm erros-padrões, os quais representam a mudança das tensões a partir da contração inicial produzida pela norepinefrina ( $60 \%$ da contração máxima a este composto). Utilizou-se indometacina na concentração de $10^{-5} \mathrm{M}$. 


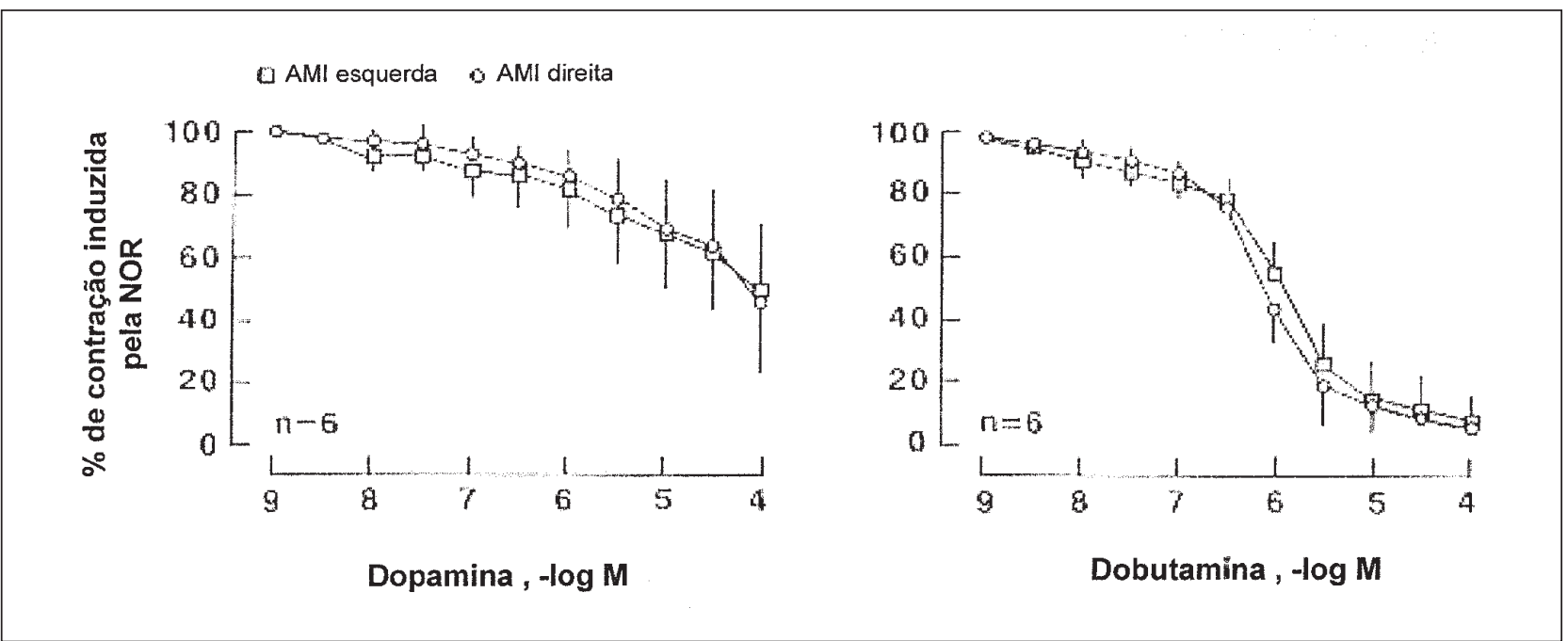

Fig. 9 - Curvas dose-respostas aos cloridratos de dopamina e dobutamina em artérias mamárias internas caninas direita e esquerda, com e sem endotélio. Apresentam-se os valores sob a forma de médias \pm erros-padrões, os quais representam a mudança das tensões a partir da contração inicial produzida pela norepinefrina ( $60 \%$ da contração máxima a este composto). Utilizou-se indometacina na concentração de $10^{-5} \mathrm{M}$.

ordem de superfusão, ou seja, não dependeu de qual artéria foi ensaiada em primeiro lugar. Além disso, não houve nenhuma diferença, estatisticamente significante, nos níveis de pré-concentrações dos "bioassays rings" anterior às superfusões de ambas as artérias. As médias das áreas superficiais, medidas por planimetria assistida por computador realizada em 19 estudos consecutivos foram, respectivamente, $251,1 \pm 8,9$ e 251,6 \pm 9,0 $\mathrm{mm}^{2}$, para as artérias direita e esquerda (média \pm erro-padrão, $p=$ NS).
Ensaio Biológico de Artérias Mamárias com a Finalidade de Testar os Efeitos da Hipóxia

A adição de prostaglandina $F_{2 \alpha}\left(2 \times 10^{-6} \mathrm{M}\right)$ ao perfusato induziu uma contração estável no "bioassay ring" coronariano. Após esta contração, alternandose o gotejamento da linha direta para as linhas da artéria mamária (superfusão endotelial), obteve-se relaxamento estável do "bioassay ring" (29,02 $\pm 2,7 \%$ e $30,67 \pm 2,36 \%$ da contração inicial, média \pm erropadrão, $n=10)$. Não houve nenhuma diferença estatisticamente significante na magnitude das

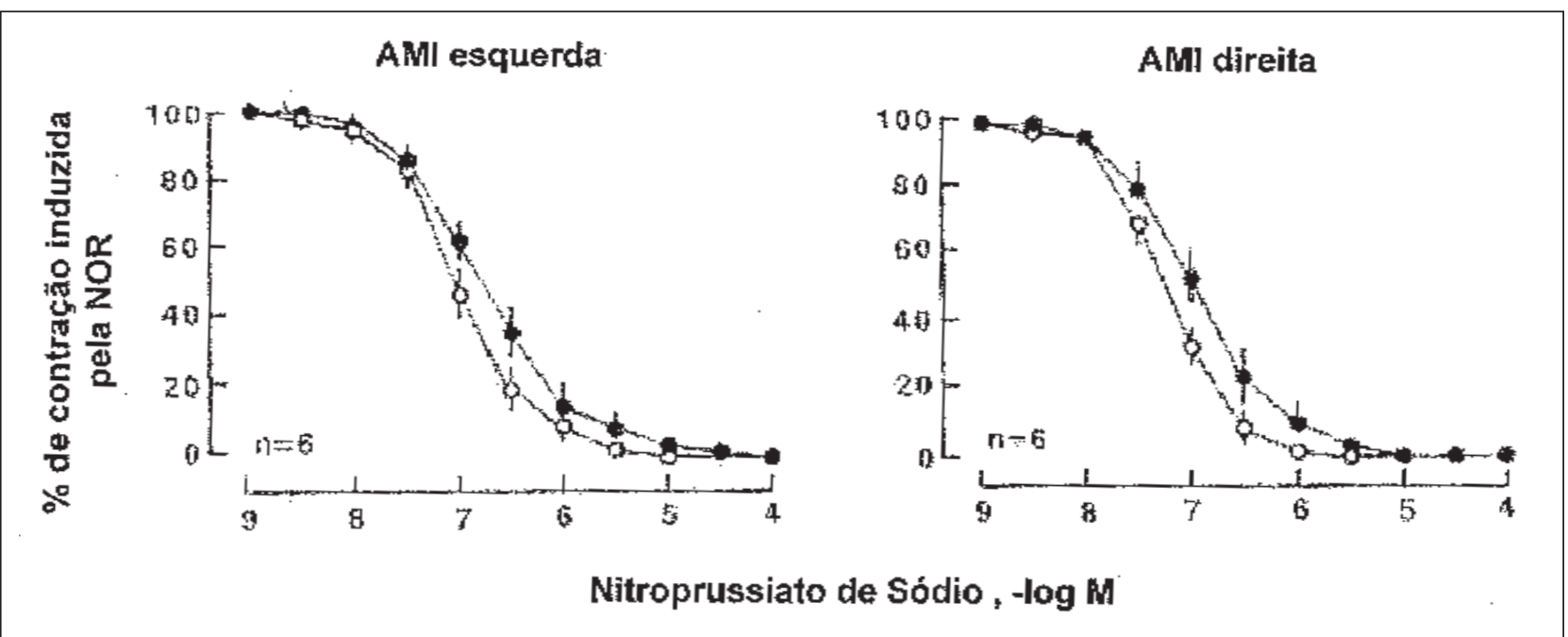

Fig. 10 - Curvas dose-respostas ao nitroprussiato de sódio $\left(10^{-9}\right.$ a $\left.10^{-4} \mathrm{M}\right)$ em artérias mamárias internas caninas direita e esquerda, com e sem endotélio. Apresentam-se os valores sob a forma de médias \pm erros-padrões, os quais representam a mudança das tensões a partir da contração inicial produzida pela norepinefrina (100\%). Utilizou-se indometacina na concentração de $10^{-5} \mathrm{M}$. 
Evora P R B, Pearson P J, Oeltjen M, Discigil B, Schaff H V - Reatividade vascular da artéria mamária interna: estudos farmacológicos comparativos entre artérias caninas direita e esquerda. Rev Bras Cir Cardiovasc 1999; 14 (4): $308-24$

TABELA 2

CONTRAÇÕES DAS ARTÉRIAS MAMÁRIAS INTERNAS CANINAS DIREITA E ESQUERDA, COM E SEM ENDOTÉLIO

\begin{tabular}{|c|c|c|c|c|}
\hline \multirow{2}{*}{ AGONISTA } & \multicolumn{2}{|c|}{$\begin{array}{c}\text { ARTÉRIA MAMÁRIA INTERNA DIREITA } \\
\text { COM ENDOTÉLIO }\end{array}$} & \multicolumn{2}{|c|}{$\begin{array}{c}\text { ARTÉRIA MAMÁRIA INTERNA ESQUERDA } \\
\text { SEM ENDOTÉLIO }\end{array}$} \\
\hline & $0,15 \pm 0,11$ & $0,52 \pm 0,36$ & $0,42 \pm 0,27$ & $0,20 \pm 0,13$ \\
\hline Íons Potássio & $3,23 \pm 0,54$ & $2,30 \pm 0,47$ & $3,77 \pm 0,70$ & $2,97 \pm 0,32$ \\
\hline Endotelina-1 & $2,90 \pm 0,40$ & $2,72 \pm 0,38$ & $3,38 \pm 0,20$ & $2,90 \pm 0,32$ \\
\hline Norepinefrina & $4,28 \pm 0,31$ & $4,42 \pm 0,40$ & $4,00 \pm 0,30$ & $3,82 \pm 0,22$ \\
\hline
\end{tabular}

$\dagger=$ Apresentam-se os valores em gramas (média \pm erro-padrão) e representam a contração máxima ao agonista testado: prostaglandina $\mathrm{F}_{2}\left(10^{-5} \mathrm{M}\right)$, íons potássio $(60 \mathrm{mM})$, endotelina-1 $\left(10^{-7} \mathrm{M}\right)$, e norepinefrina $\left(10^{-4} \mathrm{M}\right)$.

vasodilatações causadas pelos efluentes das artérias mamárias. Retornando-se a superfusão para a linha metálica direta, o relaxamento observado pelas superfusões vasculares foi, rapidamente, revertido com os "bioassay rings" retornando aos seus níveis de pré-contração. O relaxamento causado pelas superfusões de ambos os vasos pode ser prevenido pela remoção mecânica de seus endotélios, demonstrando uma liberação luminal de EDRF pela íntima dos vasos ensaiados.

A atividade vasodilatadora dos efluentes das artérias mamárias não foi afetada pela presença de indometacina $\left(10^{-6} \mathrm{M}\right)$ (bloqueador da ciclooxigenase) no fluido de perfusão. Este relaxamento foi de 29,18 $\pm 3,94 \%$ da contração inicial causada pela prostaglandina $F_{2 \alpha}$ (média \pm erro-padrão), relaxamento este não diferente dos ensaios controles sem a presença de indometacina ( $n=10$, NS $p<0,05)$, indicando que prostanóides endoteliais não estão envolvidos na produção do relaxamento produzido nos "bioassays rings". A atividade vasodilatadora dos efluentes das artérias mamárias pode ser inibida pela adição de $N^{G}$-monometil-L-arginina (L-NMMA) (10-4 M) ou de $N^{G}$-nitro-L-arginina (L-NOARG) $\left(10^{-4} \mathrm{M}\right)$ no líquido de perfusão (Figuras 12 e 13). Entretanto, LNMMA e L-NOARG não alteraram a habilidade do "bioassay ring" coronariano relaxar sob a ação do nitroprussiato de sódio $\left(10^{-7} \mathrm{M}\right)$.

A atividade vasodilatadora dos efluentes das artérias mamárias aumentou quando os vasos foram expostos à hipóxia $\left(95 \% \mathrm{~N} / 5 \% \mathrm{CO}_{2}, \mathrm{pO}_{2}=50\right.$ $\mathrm{mmg}, \mathrm{pH}-7,4)$ com valores respectivos de 50,66 $\pm 7,68 \%$ e $68,23 \pm 7,43 \%$ da contração inicial produzida pela prostaglandina $F_{2 \alpha}$ (média \pm erro-padrão, $n=10, p<0,05)$, quando comparada com os relaxamentos controles. O aumento da atividade vasodilatadora pela hipóxia foi, imediatamente, revertido com o retorno à situação de normóxia. O

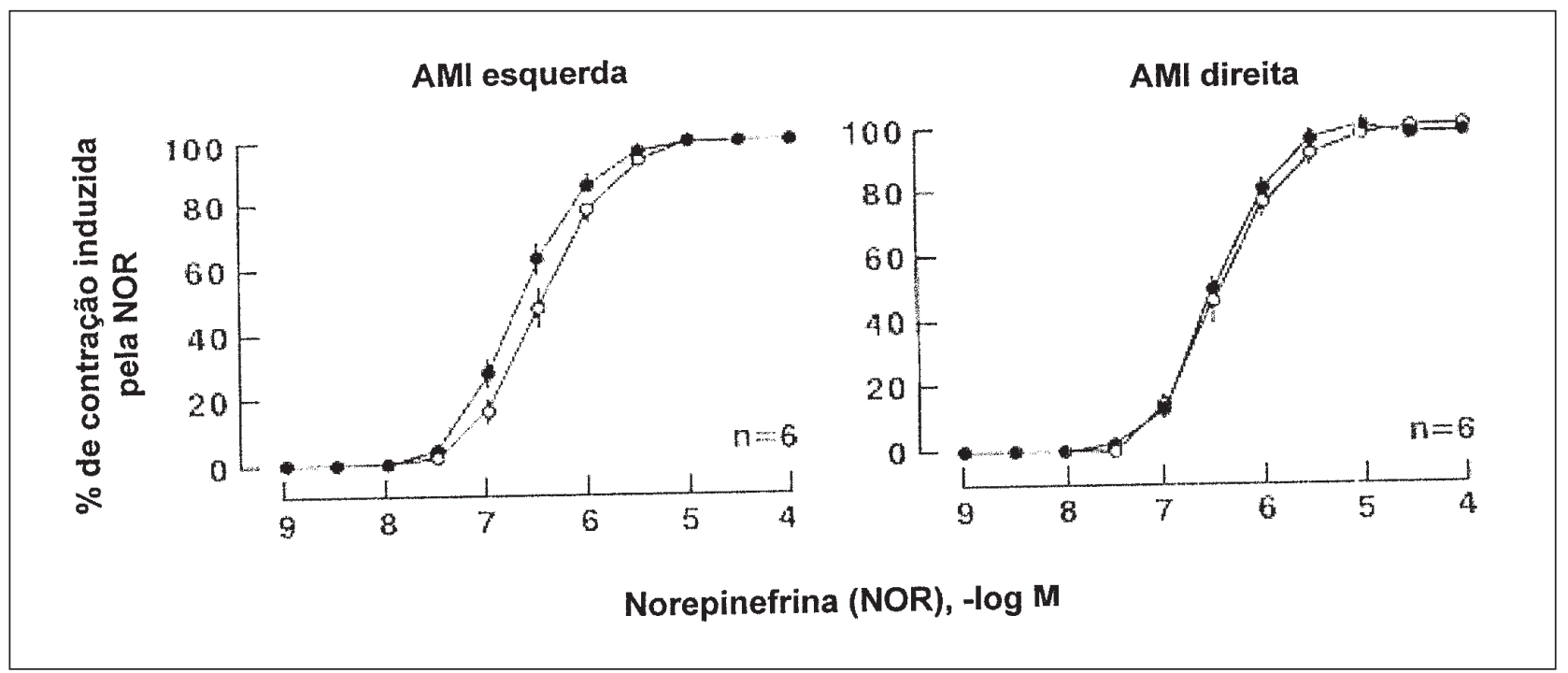

Fig. 11 - Curvas dose-respostas à norepinefrina em artérias mamárias internas caninas direita e esquerda, com e sem endotélio. Apresentam-se os valores sob a forma de médias \pm erros-padrões, os quais representam a mudança das tensões a partir da contração inicial produzida pela norepinefrina ( $60 \%$ da contração máxima a este composto). Utilizou-se indometacina na concentração de $10^{-5} \mathrm{M}$. 

comparativos entre artérias caninas direita e esquerda. Rev Bras Cir Cardiovasc 1999; 14 (4): 308-24

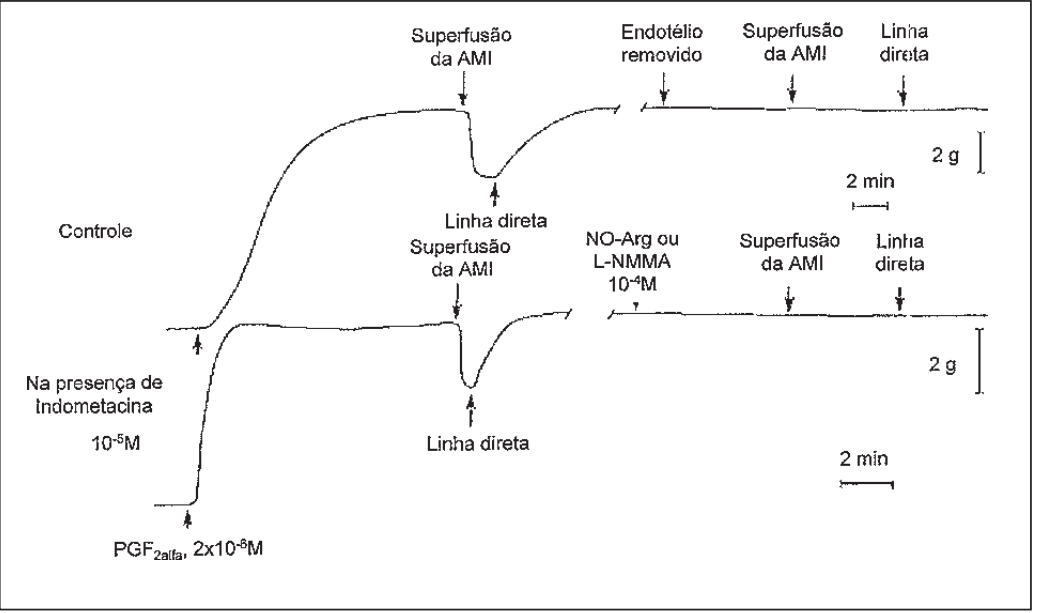

Fig. 12 - Ensaio biológico do EDRF/NO liberado pela artéria mamária esquerda (AMI) de cão (Traçado original). Perfundiram-se os segmentos arteriais com $5 \mathrm{ml} \mathrm{min}^{-1}$ de solução fisiológica controle. Quando se expôs o anel coronariano sem endotélio ("bioassay ring") à prostaglandina $\mathrm{F}_{2 \alpha}\left(2 \times 10^{-6} \mathrm{M}\right)$ através da linha prostética direta ele apresentou contração (registro superior). Entretanto, este mesmo anel sob a ação do perfusato da AMI com endotélio, apresentou relaxamento vascular indicando uma liberação basal de EDRF/NO. Retornando-se à linha direta o "bioassay ring" voltou a contrair, indicando uma remoção da ação vasodilatadora do EDRF/NO. A remoção mecânica do endotélio do segmento de AMI aboliu a ação vasodilatadora do seu perfusato (registro superior). $O$ tratamento com indometacina não alterou a atividade vasodilatadora do efluente do vaso perfundido (registro inferior). Por outro lado, o tratamento da AMI com $N^{G}$-nitro-L-arginina (L-NOARG) ou $N^{G}$-monometil-Larginina (L-NMMA) aboliu, completamente, a atividade vasodilatadora do perfusato da AMI com endotélio (registro inferior).

te, repetindo-se os experimentos com a acetilcolina $\left(10^{-5} \mathrm{M}\right)$, ela produziu significante aumento da atividade relaxante do efluente da artéria mamária tanto pela sua injeção intra como extraluminal. A atividade vasodilatadora pode ser seletivamente abolida pela administração de atropina $\left(10^{-5} \mathrm{M}\right)$ (Figuras 16-19).

\section{COMENTÁRIOS}

\section{Estudo In Vitro ("Organ Chambers") de Artérias Mamárias Direita e Es- querda}

Derivações coronarianas modulam a perfusão miocárdica por meio de um controle ativo e passivo da resistência ao fluxo sangüíneo através das pontes vasculares utilizadas para a revascularização cirúrgica (7-9). Do ponto de vista da perspectiva clínica, é importante determinar-se fatores que aumentam ou prejudicam a perfusão coronariana por meio tanto da

aumento da atividade vasodilatadora pela hipóxia, em artérias mamárias, pode ser inibido pela adição de indometacina ao perfusato (Figura 15). Entretanto, a produção de vasodilatação aumentada pela hipóxia não foi afetada pela presença de L-NMMA e N0ARG $\left(10^{-4} \mathrm{M}\right)(\mathrm{n}=3$, dados não apresentados).

Ensaio Biológico de Artérias Mamárias com a Finalidade de Testar as Ações de Agonistas Administrados Intraluminal ou Extraluminal

A perfusão intraluminal de ADP $\left(10^{-5} \mathrm{M}\right)$ (produto plaquetário que age pela estimulação de receptores de membrana da célula endotelial) ou cálcio ionóforo A23187 $\left(10^{-5} \mathrm{M}\right)$ (que age independente de receptor) induziu significante aumento da atividade relaxante do efluente da artéria mamária perfundida. Entretanto, quando estes agonistas foram ministrados extraluminalmente, não se observou nenhuma alteração na atividade relaxante do efluente. Em contras-

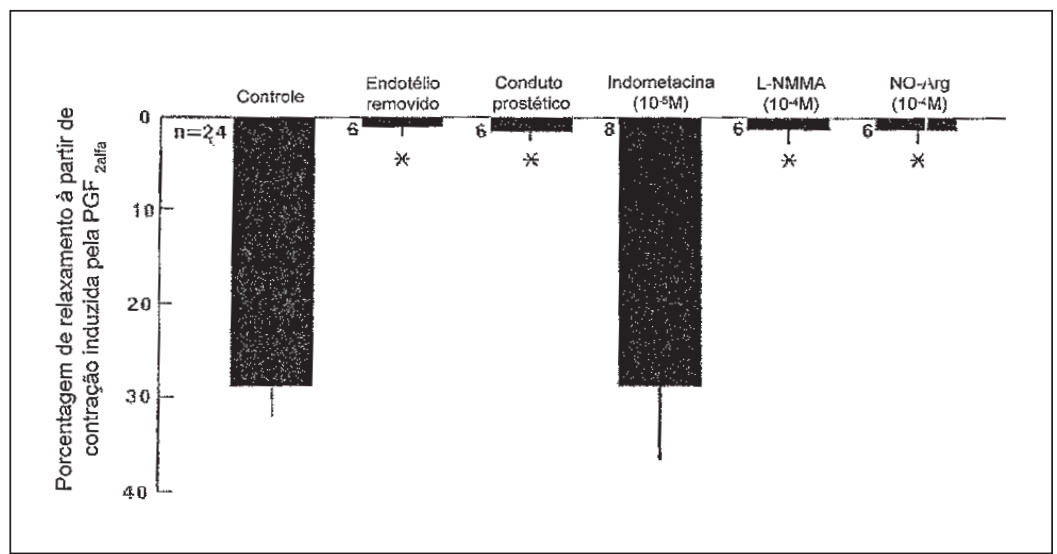

Fig. 13 - Ensaio biológico do EDRF/NO liberado pela artéria mamária esquerda (AMI) de cão. Apresentam-se os valores sob a forma de médias \pm erros-padrões e representam a porcentagem do relaxamento do anel coronariano sem endotélio ("bioassay ring") contraído com prostaglandina $\mathrm{F}_{2 \alpha}\left(2 \times 10^{-6} \mathrm{M}\right)$. Controle = relaxamento produzido pelo efluente da AMI perfundida. Endotélio removido = relaxamento produzido pelo efluente da AMI após a remoção mecânica de seu endotélio. Conduto prostético = relaxamento produzido pelo efluente através da cânula metálica. Indometacina, LNMMA ( $N^{G}$-monometil-L-arginina), e L-NOARG ( $N^{G}$-nitro-L-arginina) representam o relaxamento produzido pelo efluente de AMI perfundida após o uso destes bloqueadores. ( ${ }^{*}=\mathrm{p}<0,05$ vs relaxamento controle). 
Evora P R B, Pearson P J, Oeltjen M, Discigil B, Schaff H V - Reatividade vascular da artéria mamária interna: estudos farmacológicos comparativos entre artérias caninas direita e esquerda. Rev Bras Cir Cardiovasc 1999; 14 (4): 308-24

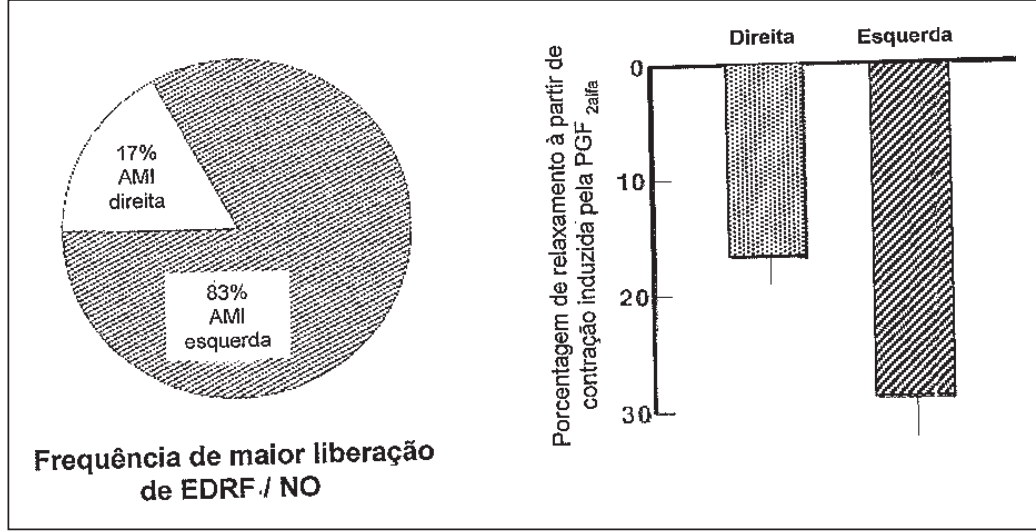

Fig. 14 - Comparação da liberação de EDRF/NO pelas artérias mamárias internas direita e esquerda.

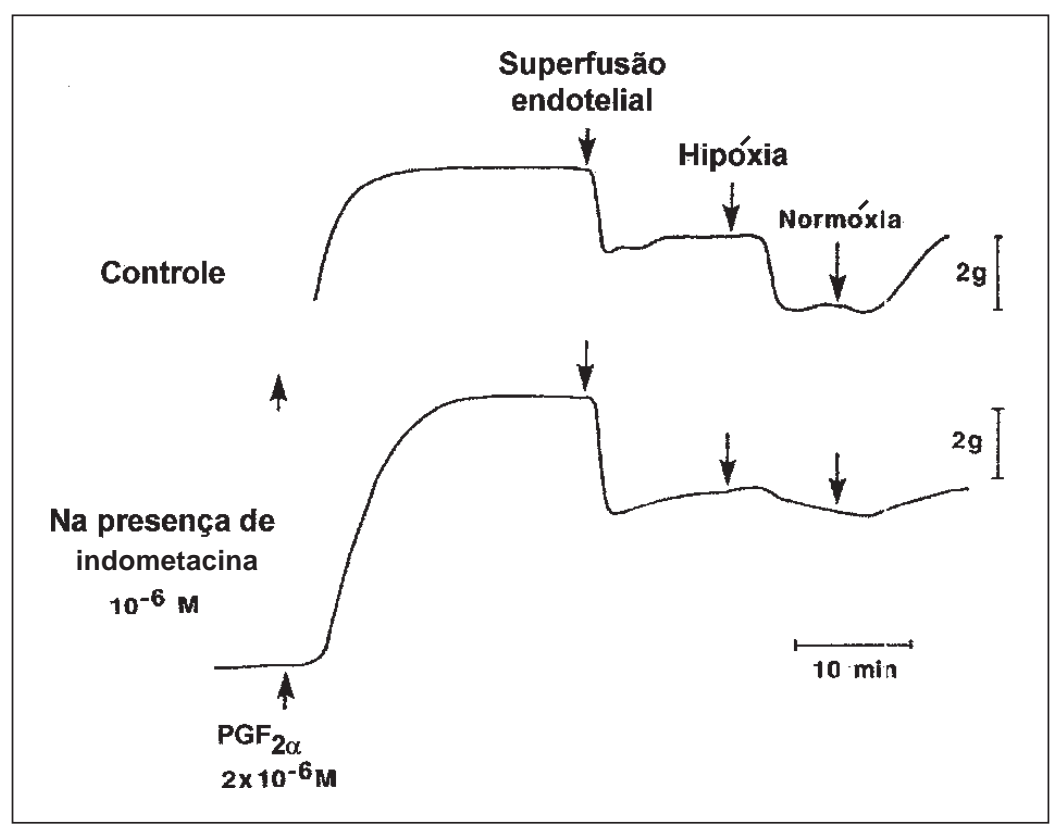

Fig. 15 - Efeito da hipóxia na liberação basal de vasodilatadores pela artéria mamária interna (AMI) canina (traçado original). Quando se expôs o anel coronariano ("bioassay ring") à prostaglandina $\mathrm{F}_{2 \alpha}\left(2 \times 10^{-6} \mathrm{M}\right)$ através da linha metálica (linha direta) observou-se contração. A exposição ao efluente da AMI com endotélio provocou um relaxamento indicando a liberação basal de EDRF/NO. Sob efeito de hipóxia (95\% $\mathrm{N}_{2} / 5 \% \mathrm{CO}_{2}$ ), observou-se um aumento da atividade vasodilatadora do efluente (registro superior). Reverteu-se, rapidamente, o aumento da atividade vasodilatadora causado pela hipóxia quando se restaurou a condição de normóxia. O tratamento com indometacina aboliu, completamente, a acentuação da vasodilatação causada pelo efluente da AMI sob as condições de hipóxia (registro inferior). endotélio a plaquetas agregadas em AMI humanas com sua íntima intacta deve-se ao ADP plaquetário atuando em receptores da célula endotelial (10). O presente experimento demonstra que se a íntima é lesada ou disfuncional, perde-se o seu efeito protetor contra a vasoconstrição mediana por plaqueta ${ }^{(11)}$. Além disso, a agregação plaquetária e o aumento da interação entre as plaquetas e a parede dos vasos sangüíneos têm implicações na oclusão das pontes coronarianas ${ }^{(12)}$. A serotonina é um outro composto liberado durante a agregação plaquetária (13). Entretanto, a serotonina induz uma modesta diminuição no tono de AMIs contraídas, agindo, diretamente, na musculatura lisa vascular. Esta ação vasodilatadora é dependente do tono, uma vez que AMls quiescentes (não contraídas), exibem constrição pela ação da serotonina ${ }^{(14-16)}$. Dois autacóides, a bradicinina e a histamina, induziram relaxamento da AMI canina, mas por diferentes mecanismos. A bradicinina causa vasodilatação, secundariamente, pela produção de EDRF. Acresça-se que a bradicinina promove a produção de EDRF na AMI de outras espécies (17). Entretanto, neste experimento a histamina, como a serotonina, induziu vasodilatação em AMls contraídas por meio de um efeito direto na musculatura lisa vascular.

Para verificar se o relaxamento dependente do endotélio da AMI canina deve-se ao EDRF/NO e não a um prostanóide, realizaram-se todos os experimentos na presença de bloqueio da ciclooxigenase pela indometacina.

O presente experimento concorda com achados experimentais em humanos (6) e confirma prévios achaautacóides e drogas cardíacas de uso clínico sobre o tono da AMI canina.

$\mathrm{Na}$ AMI canina, o ADP induziu relaxamento dependente do endotélio em segmentos arteriais. Isto concorda com achados experimentais em humanos nos quais o ADP também induz produção de EDRF/ NO (5). Esta ação tem implicação fisiologicamente importante porque a vasodilatação dependente do dos no cão $(6,11)$, nos quais descreveram-se vasodilatações dependentes do endotélio induzidas pelo cálcio ionóforo A23187 na AMI. Evidência adicional de que o relaxamento na AMI canina deve-se à liberação de EDRF/NO reside no fato de que a vasodilatação causada pelo cálcio ionóforo pode ser inibida pela hemoglobina, que é uma ávida "scavenger" (18), e um potente inibidor do óxido nítrico $(19,20)$. A vasodilatação dependente do endotélio pode também ser 


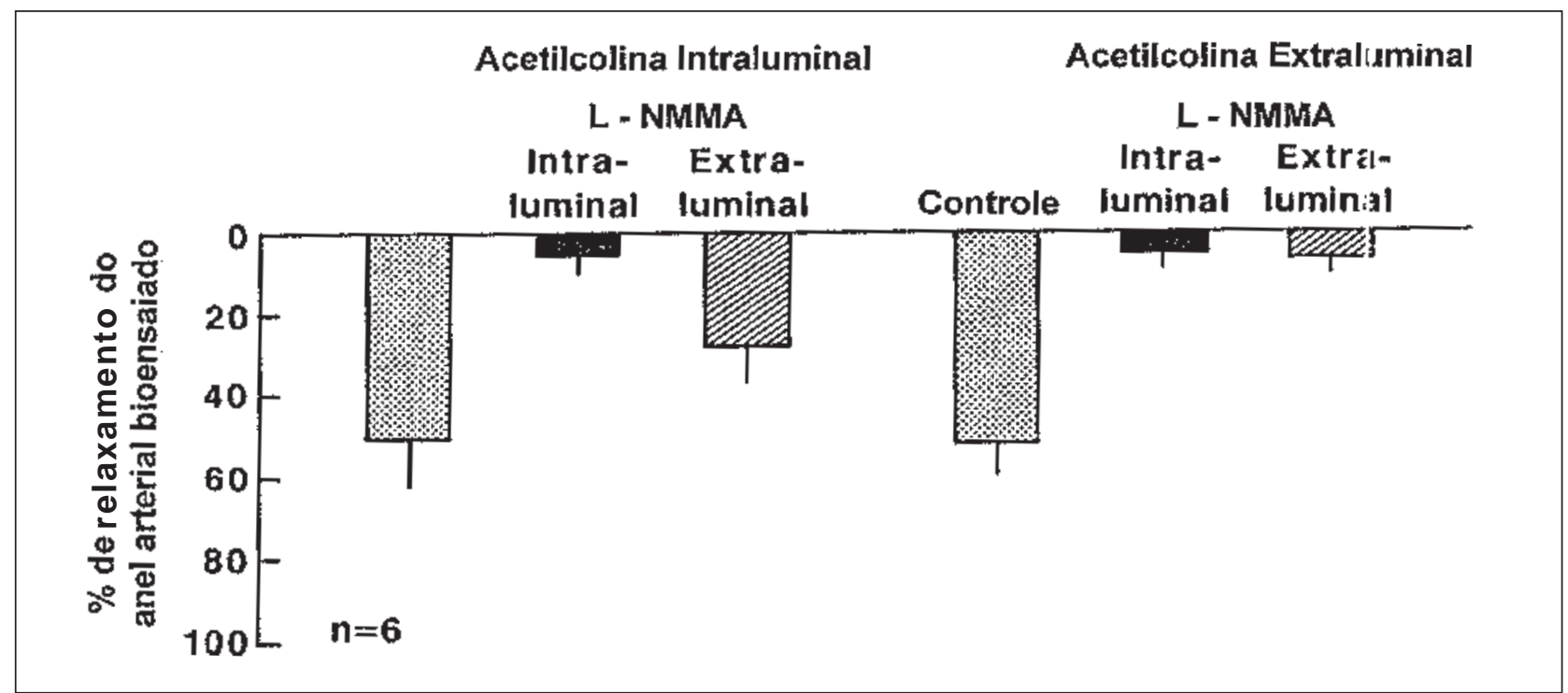

Fig. 16 - Ações da acetilcolina administrada através da artéria mamária (intraluminal) e no banho orgânico (extraluminal) na presença de indometacina. Observa-se a diminuição do relaxamento do "bioassay ring"(sem endotélio) pela ação do bloqueador L-NMMA da síntese do óxido nítrico, também administrado intra e extraluminalmente.

inibida pela $\mathrm{N}_{\mathrm{G}}$-nitro-L-arginina, que é um inibidor competitivo da síntese de óxido nítrico a partir da Larginina (21). Logo, como na AMI humana, o relaxamento dependente do endotélio na AMI canina é mediado pelo EDRF/NO atuando na musculatura lisa vascular adjacente (10).

Entre as drogas cardiovasculares clinicamente usadas estudaram-se a dopamina, a dobutamina e a papaverina. Todas induziram vasodilatação da AMI independente da presença ou não do endotélio. A relativa ordem de potência da indução de vasodilatação foi: dobutamina > papaverina > dopamina. $O$ fato de que a dobutamina e a dopamina induzem vasodilatações semelhantes à papaverina implica no fato de que estas drogas tendem a aumentar o fluxo na ponte de AMI em adição ao aumento do débito cardíaco. O fato de que a papaverina induz, prontamente, a vasodilatação da AMI é consistente

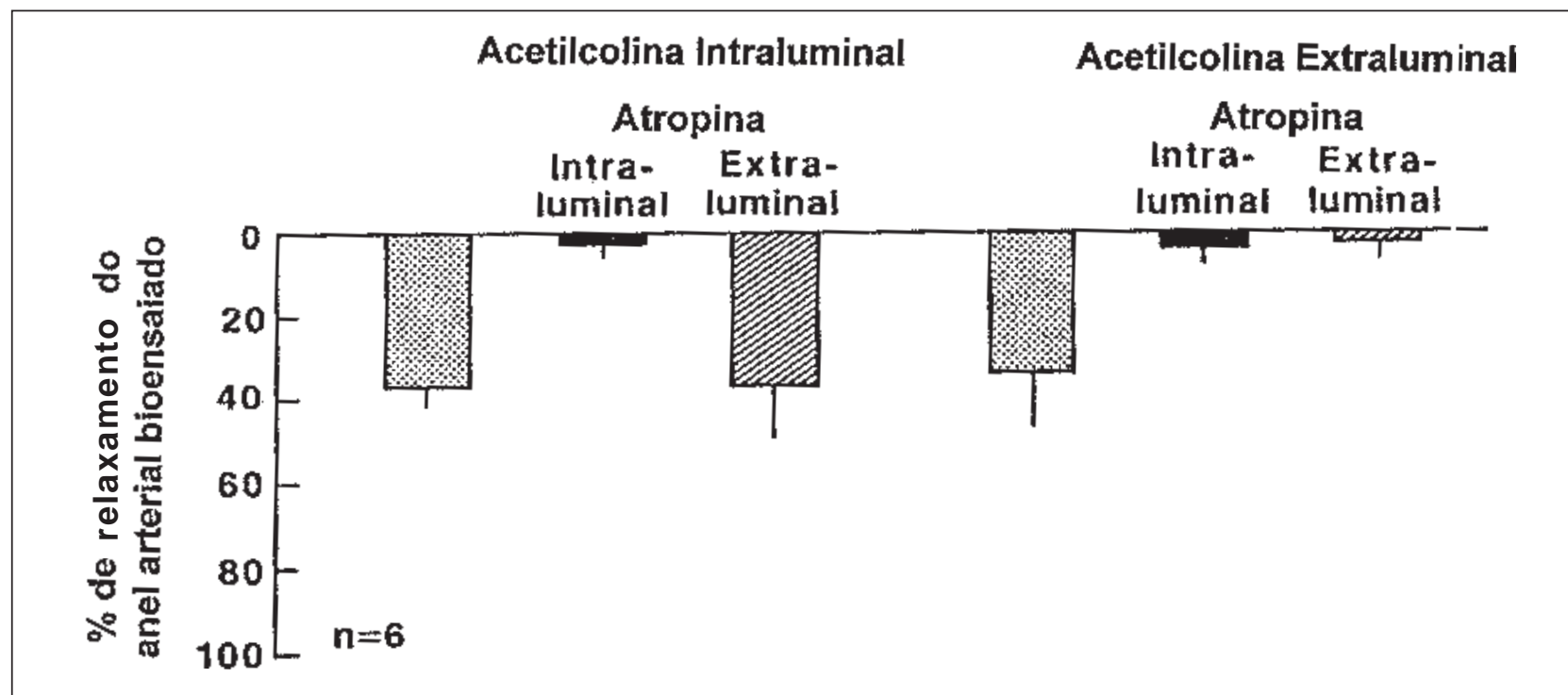

Fig. 17 - Ações da acetilcolina administrada através da artéria mamária (intraluminal) e no banho orgânico (extraluminal) na presença de indometacina. Observa-se a diminuição do relaxamento do "bioassay ring" (sem endotélio) pela ação da atropina (que bloqueia receptores muscarínicos M1 e M2), também administrada intra e extraluminalmente. 


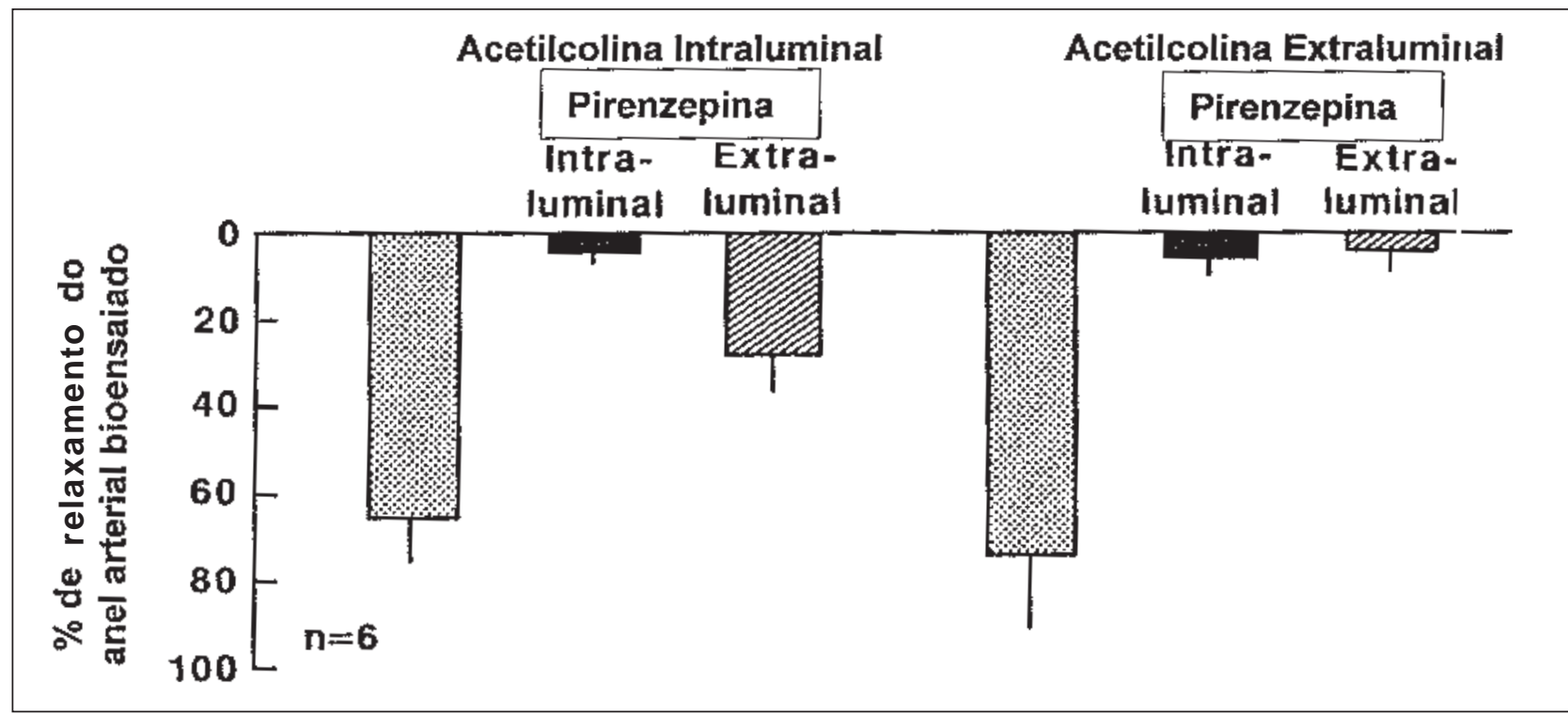

Fig. 18 - Ações da acetilcolina administrada através da artéria mamária (intraluminal) e no banho orgânico (extraluminal) na presença de indometacina. Observa-se a diminuição do relaxamento do "bioassay ring" (sem endotélio) pela ação da pirenzepina (que bloqueia receptores muscarínicos M1), também administrada intra e extraluminalmente.

com publicações clínicas que advogam o uso de papaverina durante ou imediatamente após a revascularização miocárdica com AMI (22).

No presente experimento encontrou-se que a norepinefrina causa vasoconstrição das pontes de AMI. Acresça-se que a vasoconstrição causada pela norepinefrina foi comparável aos efeitos do potássio e do peptídeo vasoconstritor endotelina. Estes achados são comparáveis aos dados obtidos em AMIs humanas, nas quais a norepinefrina é um potente vasoconstritor (14). Além disso, descreveu-se que o tratamento com norepinefrina diminuiu o fluxo em pontes de $\mathrm{AMI}$ em pacientes com hipotensão devida a hipovolemia (6).

As AMls direita e esquerda responderam de maneira semelhante a todos os agonistas testados. Ressalte-se que, em experimentos realizados em "organ chambers", o efeito da liberação abluminal de EDRF/NO na musculatura vascular lisa subjacente é medido, primariamente, sem que se possa quanti- ficar com fidelidade a liberação intraluminal o que motivou a realização dos ensaios biológicos das AMls direita e esquerda, cuja discussão será apresentada no próximo bloco. No presente experimento, não se pode afirmar que liberação de EDRF/NO (luminal e extraluminal) são comparáveis entre as AMls direita e esquerda. Como mostrar-se-a a seguir, usando-se um sistema de ensaio biológico, é provável que a liberação basal de EDRF/NO pelo endotélio da $\mathrm{AMI}$ esquerda é maior do que a do endotélio da AMI direita.

Em conclusão, estes experimentos demonstraram que produtos derivados das plaquetas, autacóides e drogas cardiovasculares exercem profundas alterações do tono vascular da AMI (Figura 20). Em adição, estes resultados observados nos estudos da AMI canina são, consistentemente, comparáveis com publicações que estudaram AMI humana. Logo, o cão é um modelo aceitável para o estudo do vasoespasmo em AMIs humanas.

\begin{tabular}{|lcc|}
\hline & ARTÉRIA MAMÁRIA INTERNA CANINA & \\
\hline & $\begin{array}{c}\text { ESTIMULAÇÃO INTRALUMINAL } \\
\text { DA PRODUÇO DE EDRF/NO }\end{array}$ & $\begin{array}{c}\text { ESTIMULAÇÃO EXTRALUMINAL } \\
\text { DA PRODUÇO DE EDRF/NO }\end{array}$ \\
\hline Acetilcolina (M1 e M2) & Sim & Sim \\
McN - A - 313 (M1) & Sim & Não \\
Difosfato de Adenosina & Sim & Não \\
lonóforo do Cálcio A23187 & Sim & Não \\
\hline
\end{tabular}

Fig. 19 - Ações da acetilcolina, ADP e ionóforo do cálcio A23187 administrados através da artéria mamária (intraluminal) e no banho orgânico (extraluminal) na presença de indometacina. 
Evora P R B, Pearson P J, Oeltjen M, Discigil B, Schaff H V - Reatividade vascular da artéria mamária interna: estudos farmacológicos comparativos entre artérias caninas direita e esquerda. Rev Bras Cir Cardiovasc 1999; 14 (4): $308-24$

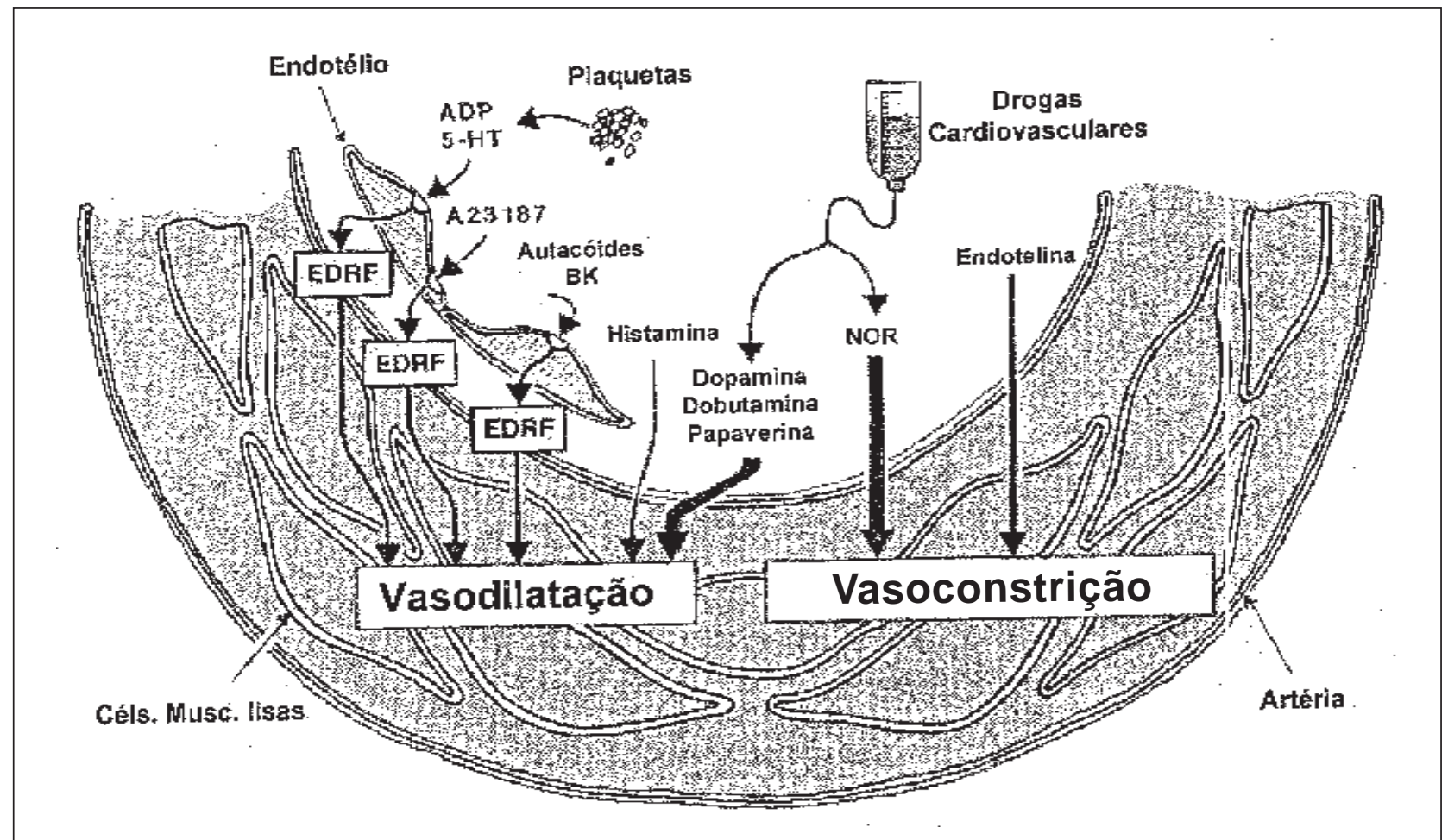

Fig. 20 - Ações vasoativas de drogas em enxertos de artéria mamária interna (AMI). Com o endotélio intacto, o autocóide bradicinina e o derivado plaquetário ADP atuam em receptores celulares para promover a síntese de EDRF/NO, o qual induz vasodilatação da musculatura lisa vascular adjacente. Se o endotélio torna-se disfuncional, o ADP, a histamina podem perder o seu efeito vasodilatador. O derivado plaquetário serotonina (5-HT) e o autacóide histamina induzem vasodilatação da AMI por ação direta na musculatura lisa vascular. Em adição, as drogas cardiovasculares dopamina, dobutamina e a papaverina são vasodilatadores diretos da musculatura lisa da AMI. Entretanto, como os vasoconstritores endógenos tipo a endotelina, concentrações crescentes de norepinefrina tendem a induzir vasoconstrição do enxerto.

\section{Ensaio Biológico de Artérias Mamárias Direita e Esquerda}

Os principais achados deste bloco de experimentos foram: 1) as artérias mamárias direita e esquerda apresentaram comparáveis liberações de EDRF/ NO pela estimulação com a acetilcolina e comparáveis vasodilatações causadas pelo nitroprussiato de sódio; 2) as artérias mamárias direita e esquerda exibiram significante liberação intraluminal de EDRF/ $\mathrm{NO}$, o qual induziu relaxamento da musculatura lisa da artéria coronária; e 3) a artéria mamária esquerda apresentou uma liberação luminal significantemente maior do que a artéria mamária direita.

A maior liberação de EDRF/NO pelos vasos arteriais pode explicar, em parte, a sua superior patência quando comparadas com veias utilizadas para revascularização do miocárdio (5). O endotélio da artéria mamária interna (AMI) produz, também, prostaciclina $(11,23,24)$. Entretanto, a quantidade de prostaciclina produzida pelo endotélio da AMI sob condições basais não é significante 0 suficiente para induzir relaxamento da musculatura lisa de artérias coronarianas epicárdicas. Acresça-se o fato de que a prostaciclina, quando comparada com o EDRF/NO, é, relativamente, um fraco vasodilatador coronariano (25).
Uma evidência adicional de que o EDRF/NO liberado pela AMI é o óxido nítrico reside no fato de que a oxihemoglobina bloqueia a vasodilatação dependente do endotélio. A oxihemoglobina "seqüestra" o radical NO e é um inibidor seletivo da vasodilatação devida ao óxido nítrico $(19,26)$. Além disso, o presente estudo mostrou que todo o óxido nítrico é gerado pela íntima vascular, pois a remoção do endotélio inibiu, completamente, a vasodilatação dependente do endotélio, tanto nos estudos em "organ chambers", como nos ensaios biológicos. Como os prostanóides, o EDRF/NO é liberado, bidirecionalmente, pelo endotélio. O EDRF/NO extraluminal atua na musculatura lisa vascular subjacente, e o EDRF/NO intraluminal é liberado para o sangue. A liberação extraluminal de EDRF/NO precocemente leva a vasodilatação da ponte de AMI. Pelo fato de que o óxido nítrico inibe a mitogênese e a proliferação de músculo liso (27), a produção extraluminal pode, a longo prazo, prevenir a aterosclerose. Há prévios estudos in vitro da função de pontes de AMls, utilizando "organ chambers" que, primariamente, medem o efeito do EDRF/NO extraluminal durante a estimulação com vários agonistas $(5,28)$.

O sistema de ensaio biológico usado neste es- 
Evora P R B, Pearson P J, Oeltjen M, Discigil B, Schaff H V-Reatividade vascular da artéria mamária interna: estudos farmacológicos comparativos entre artérias caninas direita e esquerda.

Rev Bras Cir Cardiovasc 1999; 14 (4): 308-24

tudo documentou, pela primeira vez, a liberação de EDRF/NO de AMI perfundida sob condições basais (não estimulada). No período precoce após a revascularização do miocárdio, a produção intraluminal de EDRF/NO pode ter várias ações importantes. A liberação intraluminal de EDRF/NO previne a adesividade plaquetária à parede vascular (29-32). Como o vasoespasmo é diretamente relacionado com a deposição plaquetária ${ }^{(32)}$, esta ação pode, secundariamente diminuir o tono vascular. Acresça-se que esta liberação intraluminal inibe a agregação e promove a desagregação plaquetária através de um mecanismo dependente do GMP-cíclico. Finalmente, a liberação intraluminal de EDRF/NO pode causar vasodilatação anterógrada de leitos arteriais (33) No presente experimento demonstrou-se esta atividade vasodilatadora pelo acentuado relaxamento no anel coronariano bioensaiado pelo efluente dos segmentos de AMIs perfundidas. Já que o aumento do fluxo sangüíneo aumenta a liberação luminal EDRF/ NO, espera-se que esta ação seja mais acentuada nas condições de alto fluxo in vivo (26).

Um resultado inesperado deste experimento foi a demonstração de que a AMI esquerda libera mais EDRF/NO intraluminal do que a AMI direita. Este fato não pode ser atribuído a diferentes tamanhos das artérias porque suas áreas superficiais foram iguais. Se isto for verdade, pode-se especular que as diferentes origens embriológicas das AMIs possa ter importância nesta diferença de comportamento fisiológico na liberação do EDRF/NO. A AMI direita tem sua origem embriológica no quarto arco aórtico, ao passo que a $\mathrm{AMI}$ esquerda origina-se da sétima artéria intersegmentar ${ }^{(34)}$. Existe uma heterogeneidade na produção do EDRF/NO em artérias humanas de diferentes localizações ${ }^{(35)}$. Na prática clínica, a produção intraluminal aumentada de EDRF/ $\mathrm{NO}$ pela $\mathrm{AMI}$ esquerda pode ser um fator, que somado a considerações técnico-cirúrgicas, possa explicar a sua maior patência a longo prazo em revascularizações miocárdicas, quando comparada com os resultados obtidos com a AMI direita (36).

Estes dados já foram apresentados em outras oportunidades. Como a idéia que motivou o presente trabalho foi a de apresentar um perfil farmacológico da AMI, tão completo quanto possível, optamos por inserir os dados aqui rediscutidos $(37,38)$.

Ensaio Biológico de Artérias Mamárias com a Finalidade de Testar os Efeitos da Hipóxia

Uma linha interessante de investigação implica no estudo da função endotelial na condição de hipóxia. Estes conhecimentos são extremamente importantes uma vez que problemas de perfusão miocárdica após revascularização do miocárdio com estes vasos não são infreqüentes. Nestes estudos a atividade vasodilatadora do efluente das artérias mamárias aumentou quando os vasos foram expostos à hipóxia. O aumento da atividade vasodilatadora pela hipóxia foi, imediatamente, revertido com o retorno à situação de normóxia. O aumento da atividade vasodilatadora pela hipóxia, em ambas artérias mamárias, pode ser inibido pela adição de indometacina ao perfusato (Figura 15). Estes dados ilustram, mais uma vez, o sinergismo entre EDRF/ $\mathrm{NO}$ e $\mathrm{PGI}_{2}$ e podem indicar uma particular importância do papel da prostaciclina nas condições de baixa oxigenação.

Pelas mesmas razões apresentadas para a inclusão dos dados sobre os ensaios biológicos comparativos entre as AMls direita e esquerda, estes dados já foram apresentados em outras oportunidades $(37-40)$

Ensaio Biológico de Artérias Mamárias com a Finalidade de Testar as Ações de Agonistas Administrados Intraluminal ou Extraluminal

Estes experimentos tiveram a finalidade de verificar se agonistas agem diferentemente no interior ou externamente ao vaso. O ADP (que age através de receptor) e o cálcio ionóforo A23187 (que age independente de receptor) só induziram liberação de óxido nítrico pela sua ação direta através do endotélio, ou seja, através da luz vascular. Já a acetilcolina (que age através de receptor) induz a liberação de óxido nítrico tanto em contato com a íntima vascular, como em contato externo com o vaso. Esta ação da acetilcolina pode ser seletivamente pela atropina $\left(10^{-5} \mathrm{M}\right)$. Estes experimentos indicam que certos agonistas podem induzir liberação de óxido nítrico somente pela estimulação de receptores intravasculares, enquanto outros podem induzir vasodilatação dependente do endotélio atuando em receptores extracelulares. A estimulação das liberações intravasculares versus extracelular do óxido nítrico pode ter alguma implicação funcional nos mecanismos de controle do tono vascular (41).

O conjunto de experimentos apresentados no presente trabalho, em resumo, demonstram que: 1) produtos derivados das plaquetas, autacóides e drogas cardiovasculares exercem profundas alterações no tono da AMI; 2) a liberação basal de NO, como matéria especulativa, é maior na $\mathrm{AMI}$ esquerda; 3) a $\mathrm{PGI}_{2}$ tem papel importante e sinérgico na regulação do tono da $\mathrm{AMI}$ em condições de hipóxia; 4) a estimulação da liberação intravascular versus extracelular do óxido nítrico pode ter alguma implicação funcional nos mecanismos de controle do tono vascular. 
Evora P R B, Pearson P J, Oeltjen M, Discigil B, Schaff H V-Reatividade vascular da artéria mamária interna: estudos farmacológicos comparativos entre artérias caninas direita e esquerda. Rev Bras Cir Cardiovasc 1999; 14 (4): 308-24

RBCCV 44204-473

Evora P R B, Pearson P J, Oeltjen M, Discigil B, Schaff H V - Vascular reactivity of the internal mammary artery: comparative pharmacological studies between canine right and left arteries. Rev Bras Cir Cardiovasc 1999; 14 (4): 308-24.

ABSTRACT: To study factors which modulate the tone of internal mammary artery (IMA) bypass grafts, right and left canine IMAs were studied in vitro in organ chambers: 1 ) increasing concentrations of the plateletderived products adenosine diphosphate (ADP) or serotonin (5-HT) induced vasodilation of contracted right and left IMAs. The vasodilation caused by ADP was endothelium-dependent while serotonin acted directly on the vascular smooth muscle; 2) the autacoids histamine and bradykinin also induced IMA vasodilation, histamine via a direct action on the smooth muscle, and bradykinin through the release of nitric oxide; 3 ) in canine IMAs, the calcium ionophore A23187, which acts independently of receptors produced endotheliumdependent vasodilation of contracted blood vessels; 4) dopamine, dobutamine, and papaverine induced vasodilation of the IMA, regardless of the presence or absence of an intact intima; 5) norepinephrine induced profound IMA vasoconstriction which was comparable to contraction to potassium ions or the constrictor peptide endothelin; 6 ) in $83 \%$ of 20 biological assays the basal release of nitric oxide was bigger in left IMAs than right IMAs; 7) biological assays of IMAs confirmed the importance of prostacyclin $\left(\mathrm{PGI}_{2}\right)$ in response to hypoxia; 8) no differences between right and left IMAs were observed studying the different drugs.

DESCRIPTORS: Mammary arteries, drug effects. Endothelium, vascular, drug effects. Neurotransmitters, pharmacology. Autacoids, pharmacology. Anoxia, metabolism. Nitric oxide, metabolism. Epoprostenol, metabolism. Biological assay.

AGRADECIMENTOS: À FAPESP - Fundação de Âmparo à Pesquisa do Estado de São Paulo e à Mayo Foundation, pelo apoio financeiro ao projeto.

\section{REFERÊNCIAS BIBLIOGRÁFICAS}

1 Symes J, Allard J, Huttner I et al. - Causes of perioperative myocardial infarction: their identification and prevention. Can J Surg 1980; 23: 438-41.

2 Kong B, Kopelman H, Segal B L; Iskandrian A S - Angiographic demonstration of spasm in a left internal mammary artery used as a bypass to the left anterior descending coronary artery. Am J Cardiol 1988;61: 1363.

3 Skarvan K, Graedel E, Hasse J, Stultz P, Pfisterer M Coronary artery spasm after coronary artery bypass surgery. Anesthesiology 1984; 61: 323-7.

4 Van Son J A, Smedts F, Vincent J G, Van Lier H J, Kubat $\mathrm{K}$ - Comparative anatomic studies of various arterial conduits for myocardial revascularization. $J$ Thorac Cardiovasc Surg 1990; 99: 703-7.

5 Luscher T F, Diederich D, Siebenmann R et al. Difference between endothelium-dependent relaxation in arterial and in venous coronary bypass grafts. $N$ Engl J Med 1988; 319: 462-7.

6 Yang Z \& Luscher T F - Endothelium-dependent regulatory mechanisms in human coronary bypass grafts: possible clinical implications. Z Kardiol 1989; 78: 80-4.

7 Bandyk D F, Galbraith T A, Haasler G B, Almassi G H
- Blood flow velocity of internal mammary artery and saphenous vein grafts to the coronary arteries. J Surg Res 1988; 44: 342-51.

8 Beavis R E, Mullany C J, Cronin K D et al. - An experimental in vivo study of the canine internal mammary artery and its response to vasoactive drugs. $J$ Thorac Cardiovasc Surg 1988; 95: 1059-66.

9 Lee C N, Orszulak T A, Schaff H V, Kaye M P - Flow capacity of the canine internal mammary artery. $J$ Thorac Cardiovasc Surg 1986; 91: 405-10.

10 Yang Z H, Stulz P, von Segesser L, Bauer E, Turina M, Luscher T F - Different interactions of platelets with arterial and venous coronary bupass vessels. Lancet 1991; 337: 939-43.

11 Johns R A, Peach M J, Flanagan T, Kron I L - Probing of the canine mammary artery damages endothelium and impairs vasodilation resulting from prostacyclin and endothelium-derived relaxing factor. J Thorac Cardiovasc Surg 1989; 97: 252-8.

12 Fuster V \& Chesebro J H - Role of platelets and platelet inhibitors in aortocoronary artery vein-graft disease. Circulation 1986; 73: 227-32.

13 Holmsen $\mathrm{H}$ - Platelet activation and serotonin. In: Vanhoutte PM, ed. Serotonin and the cardiovascular system. New York: Raven Press, 1985: 75-86. 
Evora P R B, Pearson P J, Oeltjen M, Discigil B, Schaff H V-Reatividade vascular da artéria mamária interna: estudos farmacológicos comparativos entre artérias caninas direita e esquerda.

Rev Bras Cir Cardiovasc 1999; 14 (4): 308-24

14 He G W, Rosenfeldt F L, Buxton B F, Angus J A Reactivity of human isolated internal mammary artery to constrictor and dilator agents: implications for treatment of internal mammary artery spasm. Circulation 1989; 80 (3 Pt 1): I-141-50.

15 Bodelsson M, Arneklo-Nobin B, Chester A H, Tadjkarimi S, Tornebrandt K, Yacoub M - Differential effect of hypothermia on the vascular tone and reactivity of the human coronary artery and graft vessels. J Cardiovasc Surg (Torino) 1991; 32: 288-94.

16 Koike R, Suma H, Kondo K et al. - Pharmacological response of internal mammary artery and gastroepiploic artery. Ann Thorac Surg 1990; 50: 384-6.

17 Thomas G, Vargas R, Wroblewska B, Ramwell P W Role of the endothelium and arginine peptides on the vasomotor response of porcine internal mammary artery. Life Sci 1989; 44: 1823-30.

18 Gibson Q H \& Roughton F J W - The kinetics and equilibria of the reactions of nitric oxide with sheep haemoglobin. J Physiol (Lond) 1957; 136: 507-26.

19 Martin W, Villani G M, Jothianandan D, Furchgott R F - Selective blockade of endothelium-dependent and glycerol trinitrate-induced relaxation by hemoglobin and by methylene blue in the rabbit aorta. $J$ Pharmacol Exp Ther 1985; 232: 708-16.

20 Martin W, Villani G M, Jothianandan D, Furchgott R F - Blockade of endothelium-dependent and glyceryl trinitrate-induced relaxation of rabbit aorta by certain ferrous hemoproteins. J Pharmacol Exp Ther 1985; 233: 679-85.

21 Moore P K, al-Swayeh O A, Chong N W, Evans R A, Gibson $A-L-N G$-nitro arginine (L-NOARG), a novel, $L$-arginine-reversible inhibitor of endotheliumdependent vasodilatation in vitro. $\mathrm{Br} J$ Pharmacol 1990; 99: 408-12.

Mills N L \& Bringaze W L III - Preparation of the internal mammary artery graft: which is the best method? $J$ Thorac Cardiovasc Surg 1989; 98: 73-9.

23 Aarnio P T, Harjula A L, Viinikka L, Merikallio E M, Mattila $S P$ - Prostacyclin production in free versus native IMA grafts. Ann Thorac Surg 1988; 45: 390-2.

24 Subramanian V A, Hernandez Y, Tack-Goldman K, Grabowski E F, Weksler B B - Prostacyclin production by internal mammary artery as a factor in coronary bypass grafts. Surgery 1986; 100: 376-83.

25 Shimokawa H, Flavahan N A, Lorenz R R, Vanhoutte P $M$ - Prostacyclin releases endothelium-derived relaxing factor and potentiates its action in coronary arteries of the pig. Br J Pharmacol 1988; 95: 1197-203.

26 Rubanyi G, Romero J C, Vanhoutte P M - Flow-induced release of endothelium-derived relaxing factor. $A m J$ Physiol 1986; 250: (6 Pt 2): H 1145-9.

27 Garg U C \& Hassid A - Nitric oxide-generating vasodilators and 8-bromo-cyclic guanosine monophosphate inhibit mitogenesis and proliferation of cultured rat vascular smooth muscle cells. J Clin Invest 1989; 83: 1774-7.

28 Lin $\mathrm{P} \mathrm{J}$, Pearson $\mathrm{P} J$, Schaff $\mathrm{H} \mathrm{V} \mathrm{-} \mathrm{Endothelium-}$ dependent contraction and relaxation of the human and canine internal mammary artery: studies on bypass graft vasospasm. Surgery 1991;110: 127-35.

29 Radomski M W, Palmer R M, Moncada S - Comparative pharmacology of endothelium-derived relaxing factor, nitric oxide and prostacyclin in platelets. $\mathrm{Br} J$ Pharmacol 1987; 92: 181-7.

30 Radomski M W, Palmer R M, Moncada S - The antiaggregating properties of vascular endothelium: interactions between prostacyclin and nitric oxide. $\mathrm{Br}$ J Pharmacol 1987; 92: 639-46.

31 Radomski M W, Palmer R M, Moncada S - Endogenous nitric oxide inhibits human platelet adhesion to vascular endothelium. Lancet 1987; 2: 1057-8.

32 Lam J Y, Chesebro J H, Steele P M, Badimon L, Fuster $\mathrm{V}$ - Is vasospasm related to platelet deposition? Relationship in a porcine preparation of arterial injury in vivo. Circulation 1987; 75: 243-8.

33 Kelm M \& Schrader J - Control of coronary vascular tone by nitric oxide. Circ Res 1990; 66: 1561-75.

34 Moore $\mathrm{K} \mathrm{L}$ - The developing human: clinically-oriented embryology. 2 ed. Philadelphia: W B Saunders, 1977: 277-8.

35 Thom S, Hughes A, Martin G, Sever P S - Endotheliumdependent relaxation in isolated human arteries and veins. Clin Sci 1987; 73: 547-52.

36 Huddleston C B, Stoney W S, Alford W C Jr. et al. - Internal mammary artery grafts: technical factors influencing patency. Ann Thorac Surg 1986; 42: 543-9.

37 Pearson $\mathrm{P}$ J, Evora $\mathrm{P} \mathrm{R}$, Schaff $\mathrm{H} \mathrm{V}$ - Bioassay of endothelium-derived relaxing factor (EDRF) from internal mammary arteries: implications for early and late bypass graft patency. Ann Thorac Surg 1992; 54: 1078-84.

38 Pearson P J, Evora P R, Discigil B, Schaff H V - Hypoxia increases vasodilator release from internal mammary artery and saphenous vein grafts. Ann Thorac Surg 1998; 65: 1220-5.

39 Evora P R B, Pearson P J, Discigil B, Seccombe J F, Oeltjen M, Schaff H V - Óxido nítrico e substâncias vasoativas derivadas do endotélio: papel no controle do tonus vascular. Rev Soc Cardiol de São Paulo 1996; 6: 129-37.

40 Evora P R B, Pearson P J, Schaff H V - Alguns aspectos da função endotelial em cirurgia cardíaca. Rev Bras Cir Cardiovasc 1993: 8: 195-214.

41 Pearson P J, Evora P R B, Schaff H V - Luminal release of endothelium-derived relaxing factor (EDRF) in the perfused internal mammary artery: selective stimulation by intra-luminal and extra-luminal receptors. FASEB J 1992; 6: A2019. 